\title{
Ambiguity Aversion and Stock Market Participation: An Empirical Analysis
}

\author{
Constantinos Antoniou, Richard D. F. Harris, Ruogu Zhang* \\ $1^{\text {st }}$ Draft: February 2013 \\ This draft: March 2015
}

\begin{abstract}
Theoretical models of portfolio choice that incorporate ambiguity predict that investors' propensity to invest in stocks is reduced when ambiguity in the market increases. Although this hypothesis stems from the extant theoretical literature, there is no empirical work examining whether it is supported in the data. We test this hypothesis, measuring participation using equity fund flows and ambiguity with dispersion in analyst forecasts about aggregate returns. Our results confirm this hypothesis, as we show that, controlling for other factors that affect flows, increases in ambiguity are associated with outflows from equity funds. Moreover, using data from the Survey of Consumer Finances, we find that increases in ambiguity significantly reduce the likelihood that the average household invests in equities.
\end{abstract}

Keywords: Stock market participation; ambiguity aversion; fund flows.

JEL Classification: D140, D81, G11.

\footnotetext{
*Warwick Business School, University of Warwick (Antoniou, corresponding author), University of Exeter Business School, University of Exeter (Harris and Zhang). E-mails: constantinos.antoniou@wbs.ac.uk (Antoniou), R.D.F.Harris@exeter.ac.uk (Harris),rgz201@exeter.ac.uk (Zhang). We thank Carol Alexander (the editor), two anonymous referees, Emilios Galariotis, Xing Jin, Roman Kozhan, F.Y. Eric C. Lam (discussant), Giakomo Nocera, Alessandro Palandri, Rajesh Tharyan, Grzegorz Trojanowski, Christophe Villa, Peter Wakker and seminar and conference participants at the University of Exeter, Audencia Nantes, the European Financial Management 2013 meeting and the 2014 Research in Behavioural Finance meeting at Erasmus University for useful comments and suggestions. We also thank the Investment Company Institute (ICI) for providing us with the data on fund flows and Mark Kamstra for sharing the data on advertising expenses.
} 


\section{Introduction}

Since the seminal work of Ellsberg (1961), research in experimental economics and psychology has shown that people tend to be averse to conditions of ambiguity, where the probabilities associated with different states of nature are unknown. ${ }^{1}$ Several authors have argued that ambiguity is relevant to financial markets, since the probabilities that underlie the distribution of asset returns are not explicitly known. Motivated by this observation, the notion of ambiguity has received several applications in finance. ${ }^{2}$ A robust prediction from theoretical models of portfolio choice is that, in the presence of ambiguity, stock market participation tends to be lower than predicted from the basic EU model, and negatively related to changes in ambiguity in the market (i.e., Dow and Werlang, 1992; Maenhout, 2004; Cao, Wang and Zhang, 2005; Garlappi et al., 2007; Easley and O'Hara, 2009; Epstein and Schneider, 2010). This prediction, however, remains untested in naturally-occurring, financial data. In this paper we fill this void by empirically testing the hypothesis.

The starting point for our analysis is the notion that for non-professional investors, the principal avenue for stock market participation is through mutual funds. The Investment Company Institute (ICI) estimates that in 2011, households owned 89 percent of the mutual fund industry (ICI Factbook, 2012). Therefore, flows in and out of mutual funds reflect the active reallocation decisions of individual investors, and thus provide a direct measure of stock market participation. We use two empirical proxies to capture these shifts: mutual fund net flows, i.e. the net cash flow into equity funds, and mutual fund exchanges, i.e. the switch of capital between funds of different asset classes that are managed by the same investment

\footnotetext{
${ }^{1}$ Hsu et al. (2005) and Levy et al. (2010) present evidence that ambiguous situations produce a unique neurological fingerprint, suggesting that ambiguity aversion is rooted in the fundamentals of human cognition. See Camerer and Weber (1992) and Keren and Gerritsen (1999) for reviews of the evidence on ambiguity aversion.

${ }^{2}$ For reviews of this literature see Mukerji and Tallon (2001), Epstein and Schneider, (2010) and Guidolin and Rinaldi (2013).
} 
house. Whilst the first measure captures stock market participation in absolute terms, the second, proposed by Ben-Rephael et al. (2012), provides a stock-market participation metric that is relative to other asset classes.

To test the hypothesis we require an empirical measure of ambiguity. To this end we rely on the measure proposed in a recent study by Anderson et al. (2009), which is based on dispersion in analysts' forecasts using data from the Survey of Professional Forecasters (SPF), issued by the Federal Reserve. The SPF contains quarterly forecasts of GDP growth and inflation from different analysts, and following Anderson et al. (2009) we use the Gordon Growth Model to derive a forecast for aggregate stock market returns for each analyst. ${ }^{3}$ When dispersion among analysts regarding the future performance of stock markets is high, ambiguity is also likely to be high since experts have arrived at conflicting views regarding the fundamentals of the economy. In these conditions investors can be thought to face multiple plausible distributions of expected equity returns, which indicate higher ambiguity.

This approach of measuring ambiguity, which has been employed by several other studies in finance (Ulrich, 2013; Drechsler, 2012; Shi, 2013), corresponds closely to the original definitions provided by Ellsberg (1961), who in his seminal paper noted that ".. it should be possible to identify "objectively" some situations likely to present high ambiguity, by noting situations where ... expressed expectations of different individuals differ widely;" Ellsberg (1961, p. 660). Thus, according to Ellsberg (1961), when different individuals arrive at conflicting views (i.e., when dispersion is high), the underlying distribution can be described as more ambiguous. Moreover, this approach is in line with the asset pricing literature that models ambiguity as uncertainty about the model generating returns (e.g., Hansen and Sargent, 2001). Since each individual analyst relies on his preferred model to make a prediction, high dispersion between analysts signals a situation where different

\footnotetext{
${ }^{3}$ The forecast data is available at http://www.phil.frb.org/econ/spf/index.html.
} 
models are possible and, therefore, there is increased ambiguity. We discuss this issue in more detail in section 3.2 of the paper.

Using data on U.S. fund flows from the Investment Company Institute, we examine whether ambiguity is negatively related to capital flows into equity mutual funds. To ensure that the ambiguity measure we use is not simply capturing risk, we include a measure of market risk in our regressions, calculated as a weighted average of past daily squared excess market returns, as in Andersen et al. (2009). We also control for other factors that have been shown to be important when modelling investors decisions to change their holdings in mutual funds: past fund returns (Ippolito, 1992; Sirri and Tufano, 1998), capital gains ((Kamstra, Kramer, Levi and Wermers, 2014), past flows (Ben-Rephael, Kandel, and Wohl, 2011), seasonal effects (Kamstra et al., 2014), advertising expenses (Gallaher, et al., 2006), past market returns (Ben-Rephael, et al., 2012) and savings (Kamstra et al., 2014). Our results show that controlling for other factors that affect changes in flows, increases in ambiguity are associated with reductions in capital moving into equity mutual funds. This finding confirms the prediction of the theoretical ambiguity literature, that market participation is negatively related to ambiguity aversion.

When we dissect equity flows into different equity categories, we find that the effect of ambiguity is more pronounced for funds classed as 'aggressive growth' and 'growth', which tend to invest more heavily in non-dividend paying firms. Such firms, which rely on capital gains to make payoffs to investors, can be thought of as being more ambiguous than dividend-paying firms. This is because dividends are relatively predictable, due to fact that dividend-policy tends to be "sticky" (e.g., Denis and Osobov, 2008). Our findings, therefore, suggest that investors perceive capital gains as more ambiguous, and therefore avoid 'aggressive growth' and 'growth' funds in periods of high ambiguity. 
We also analyse the effect of ambiguity on participation in non-equity mutual funds and find some evidence that ambiguity is negatively related to flows and exchanges into government and corporate fixed income funds, and positively related to exchanges into money market funds. This suggests that in periods of high stock market ambiguity, investors avoid both equities and fixed income assets, and seek the safety of a safer and more liquid asset class.

Even though the Anderson et al (2009) measure corresponds closely to the definitions of ambiguity provided by Ellsberg (1961), there is still a concern that it may be related to market risk or market sentiment. Since these factors can also affect stock market participation decisions, we conduct additional tests to ensure that the negative relationship between ambiguity and participation that we document is not related to sentiment or risk. To account for sentiment, we repeat our baseline analysis by including two additional variables that can capture errors in expectations, namely the sentiment index constructed in Baker and Wurgler (2007), and the median SPF forecast for expected market returns. ${ }^{4}$ We find that our results continue to hold in this specification. In terms of risk, we estimate our baseline model using additional risk specifications: realized volatility, forecasts of volatility from GARCH models and the Chicago Board Options Exchange (CBOE) volatility index. Even though the risk variables are generally negative and significant, ambiguity continues to exert a significant negative impact on capital flows into equities in all models, which suggests that it is not simply capturing risk. We discuss our robustness tests in detail in section 4.5 of the paper.

Ambiguity theories, apart from predicting a negative relationship between ambiguity and capital invested in equities, also predict that the proportion of households that participate in equities drops when ambiguity increases. Since fund flows capture this effect only

\footnotetext{
${ }^{4}$ High values of the Baker and Wurgler sentiment index have been argued to correspond to overly optimistic beliefs (Baker and Wurgler, 2006). In addition, as shown by Hribar and McInnis (2012) and Antoniou, Doukas and Subrahmanyam (2014), analyst optimism is also an indication of optimistic sentiment.
} 
partially, ${ }^{5}$ we test this prediction more directly using data from the household of Consumer Finances Surveys, going back to 1990 . We use a logistic model, where the dependent variable is a binary indicator of stock market participation. We include various control variables in the model that can affect participation decisions, such as risk attitude, education and income level, along with our ambiguity variable and controls for market risk and market trends. In line with our previous findings, we find that the probability that households invest in equities is significantly reduced when ambiguity is higher, which provides further confirmatory evidence that ambiguity adversely affects stock market participation.

Various behavioural factors have been shown to affect stock market participation, such as social interaction (Hong et al., 2004), cognitive ability (Grinblatt et al., 2012), and trust (Guiso, Sapienza and Zingales, 2008). Ambiguity aversion is another behavioural factor that has been theoretically linked to stock-market participation (Epstein and Schneider 2010), but, thus far empirical tests of this prediction are mainly based on survey data, with mixed results. In a contemporaneous study Dimmock et al. (2013) elicit ambiguity attitudes using online questionnaires, and find that more ambiguity averse individuals participate less in the stock market. In an earlier survey-based study Guiso et al. (2008) show that ambiguity attitude does not affect stock market participation decisions. Our study complements this work by providing further empirical evidence on the effect of ambiguity on stock market participation, exploiting naturally-occurring financial data. ${ }^{6}$

Our study also contributes to the literature that analyses the determinants of fund flows. Jain and Wu (2000) and Kacperczyk and Seru (2007) show that fund flows are related to funds' advertising expenses and the ability of the fund manager, respectively. Ivkovich and Weisbenner (2009) show that flows are affected by past fund performance, expense ratios and

\footnotetext{
${ }^{5}$ This is because outflows will reflect both the complete withdrawal of some investors from equity markets, and also the scaling down of existing positions.

${ }^{6}$ For other studies that provide empirical evidence on the effects of ambiguity in the marketplace see Brenner and Izhakian (2011), Antoniou et al. (2014) and Kelsey et al. (2008).
} 
loads. Cooper et al. (2005) show that flows are affected by catering effects via name changes, and Kamstra et al. (2014) show that flows are affected by seasonal variations in risk aversion. Our study shows that flows are negatively related to ambiguity about future stock market returns.

\section{Ambiguity and market participation}

In this section we use a simple model with a representative agent to develop our hypothesis, following the exposition in Cao, Wang and Zhang (2005). As is well known, in the basic EU model with a one-period endowment economy, a representative CARA agent, a risky asset, $r$, with mean payoff of $\mu$, variance $\sigma^{2}$ and price $P,{ }^{7}$ and a risk-free rate set to zero, the optimal weight, $D$, put on the risky asset is,

$$
D=\frac{\mu-P}{\gamma \sigma^{2}}
$$

$D$ reflects the stock market participation of this agent. The agent is long $(D>0)$ when she expects the premium to be positive $(\mu-P>0)$, and short $(D<0)$ when she expects it to be negative $(\mu-P<0)$, proportional to her risk attitude and level of risk. Importantly, $D$ is never zero so the agent is always optimally long or short in the risky asset.

In this model it is implicitly assumed that the decision maker is able to uniquely estimate a conditional probability distribution for the asset payoffs, and is thus making a decision under conditions of risk. Ambiguity, however, is a situation in which the decision maker does not have enough information to arrive at a single probability distribution and faces a situation where multiple likelihoods can plausibly arise. In this situation, as argued initially by Ellsberg (1961), the agent appears to be pessimistic, making his decision based on the worst-case likelihood. ${ }^{8}$

\footnotetext{
${ }^{7}$ The risky asset in this framework can be thought of as the market portfolio in a CAPM-type economy.

${ }^{8}$ For further discussion on max-min preferences, see the original contribution by Gilboa and Schmeidler (1989), and various developments and applications discussed in Epstein and Schneider (2010) and Guidolin and Rinaldi (2013).
} 
Following Cao et al. (2005), we incorporate ambiguity in the model above by assuming that the agent faces multiple possible distributions for the risky asset, each with a different expected payoff: $\mathbb{E}_{t}\left[r_{t+1}^{j}\right] \in[\mu-\Delta, \mu+\Delta]$. The level of ambiguity, $\Delta$, captures the lack of information regarding the mean payoff, where higher $\Delta$ is indicative of higher ambiguity. Being ambiguity averse, the agent will choose her market participation using the worst possible distribution from this set, which will result in the following:

$$
D=\left\{\begin{array}{r}
\frac{1}{\gamma \sigma^{2}}(\mu-\Delta-P) \text { if } \mu-P>\Delta \\
0 \quad \text { if }-\Delta \leq \mu-P \leq \Delta \\
\frac{1}{\gamma \sigma^{2}}(\mu+\Delta-P) \text { if } \mu-P<\Delta
\end{array}\right.
$$

As shown in Equation 2 the agent decides her participation using the worst case expected premium. When the agent is long, she expects the lowest possible premium, and when she is short she expects the highest possible premium. In addition, as shown initially by Dow and Werlang (1992), there is a "no trade-zone", whereby, for given parameters, the agent rationally abstains from the risky asset altogether.

Equation 2 nicely highlights the two facets of limited market participation due to ambiguity, which form the hypothesis we test in this study:

$H_{l}$ : All else equal, an increase in ambiguity will result in a reduction in the amount of capital channeled into equity markets $\left(1^{\text {st }}\right.$ and $3^{\text {rd }}$ row $)$.

$H_{2}$ : An increase in ambiguity will lead to a larger proportion of abstaining households $\left(2^{\text {nd }}\right.$ row).

The following sections test these hypotheses. 


\section{Data and Methodology}

\subsection{Mutual Fund Flows and Exchanges}

Our main source of fund data is the Investment Company Institute (ICI), which provides detailed information about the monthly flows to thirty mutual fund investment categories. Our sample covers the period March 1985 to December 2010. For each fund category, ICI reports monthly data on sales, redemptions, exchanges, reinvested distributions and total net assets. We divide the thirty ICI investment objective categories into five groups by asset class using the categorization proposed by Kamstra et al. (2014), namely equity, hybrid, corporate fixed income, government fixed income and money market. Our main focus is the equity asset class, which comprises funds classified as 'aggressive growth', 'growth', 'sector', 'growth and income', and 'income equity'. Moreover, since the ambiguity measure that we construct is for the U.S. stock market, we omit the equity investment objective categories that represent investments outside of the U.S., i.e. 'global equity', 'international equity', 'regional equity' and 'emerging markets'. When we analyse flows into non-equity funds we eliminate the 'global bond - general', 'global bond - short term' and 'other world bond' fund categories. In Table 1 we report the classification of funds by investment objective category.

[Table 1 here]

We compute the net cash inflow into asset class $i$ in month $t$ as:

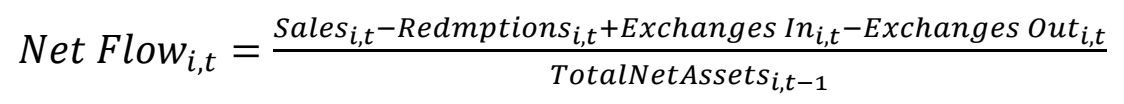

Similarly, following Ben-Rephael et al. (2012), we compute the net exchange into asset class $i$ in month $t$ as:

$$
\text { Net Exchang } e_{i, t}=\frac{\text { ExchangesIn }_{i, t}-\text { ExchangesOut }_{i, t}}{\text { TotalNetAssets }_{i, t-1}}
$$

In our empirical tests, Net Exchange $e_{i, t}$, captures the net exchange from fund category $i$ (i.e., equities) into all the remaining $i-1$ categories (i.e., bonds, etc) at time $t$, using the categorization of Kamstra et al (2014), shown in Table 1. As explained in Ben-Rephael et al. 
(2012) and Kamstra et al. (2014), since "exchanges in" and "exchanges out" are transfers of already invested capital between different types of funds managed by the same investment house, Net Exchange Ext, $_{\text {, }}$ provides a relative metric of changes in participation for each asset class, vis-à-vis all the other asset classes, which is less confounded by other factors, such as liquidity considerations, year-end bonuses or changes in savings and consumption behaviours.

Figure 1 plots the net flows and exchanges for the equity group of funds. Net flows and exchanges into equity were very much more volatile before 1993, with a large flow out of the equity asset class following the October 1987 crash. Since 1994, net flows and net exchanges have been less volatile, but also declining. Table 2 reports summary statistics for the net flows and exchanges for the equity asset class. The average net flow is $0.51 \%$, representing a substantial increase in total net assets over the sample, while the average net exchange is close to zero. Net exchanges are negatively skewed and strongly leptokurtic, while net flows have much lower skewness and kurtosis.

[Figure 1 here]

[Table 2 here]

\subsection{Ambiguity}

The notion of ambiguity was initially developed by Knight (1921) and Keynes (1921), and describes a situation where the probabilities associated with future states of nature are unknown. Ellsberg (1961) was the first to conjecture that people are particularly averse to ambiguity, a hypothesis subsequently confirmed by many studies in experimental economics and psychology.

Given the importance of ambiguity on decision making, a large theoretical literature in finance and economics has applied the concept to problems of portfolio choice, and was 
able to resolve many puzzles that could not be explained by the EU model. ${ }^{9}$ However, despite the vast array of theoretical predictions made by these models, there is a paucity of empirical work on these issues, mainly because it is difficult to measure ambiguity in financial data. However, recent studies such as Anderson et al. (2009) have made significant advances on this front, by revisiting the original definitions of ambiguity and designing measures that accord with these definitions. For example Ellsberg (1961), in his seminal paper, defined ambiguity as follows: "Ambiguity is a subjective variable, but it should be possible to identify "objectively" some situations likely to present high ambiguity, by noting situations where available information is scanty or obviously unreliable or highly conflicting; or where expressed expectations of different individuals differ widely;" Ellsberg (1961, p. 660). Ellsberg thus views ambiguity as negatively related to what might be called the "richness" of the information that is available to compute the likelihood of interest, ${ }^{10}$ and suggests two broad ways to empirically measure ambiguity: Either by quantifying the richness of the information directly; or by inferring this richness indirectly using as an index the disagreement between different users of the information set.

In our study we use the empirical measure of ambiguity proposed by Anderson et al. (2009) which is based on the latter approach. This measure reflects disagreement among experts regarding aggregate economic performance in the future. Experts analyse the available information related to the future prospects of the economy, form a subjective probability distribution and report the mean of this distribution as their forecast. A high level

\footnotetext{
${ }^{9}$ See Mukerji and Tallon (2001) and Epstein and Schneider (2010) for reviews of this literature.

${ }^{10}$ This view is common among decision theorists. Frisch and Baron (1988) proposed that "ambiguity is uncertainty about probability, created by missing information that is relevant and could be known" (P. 1988). Einhorn and Hogarth (1985) suggest that ambiguous situations arise when the available information is vague, and does not allow one to confidently rule out alternative possibilities, while Gärdenfors and Sahlin $(1982,1983)$ argue that feelings of ambiguity are produced when the relevance of the available information is low.
} 
of disagreement amongst these experts implies incomplete information regarding the generating process and, therefore, increased ambiguity. ${ }^{11}$

The data to calculate this measure are taken from the Federal Reserve's Survey of Professional Forecasters (SPF), which reports the individual forecasts made by large financial institutions of a number of U.S. economic and financial variables, for a range of forecast horizons including the last quarter (the actual value of which may not have been published at the time the forecast is made) and the following four quarters, as well as for annual and longer horizons. The forecast data is available on a quarterly basis from 1968, and represents the views of between a minimum of nine and a maximum of 74 participants. Following Anderson et al. (2009), we use forecasts of aggregate output, the output deflator, and corporate profits after taxes. ${ }^{12}$ Following the procedure in Anderson et al. (2009) we first calculate an approximation of the forecast at time $t$ of real aggregate corporate profit at time $t+1$ for forecaster $i$ as:

$$
E_{i t}\left(\pi_{t+1}\right)=\frac{E_{i t}\left(\tau_{t+1}\right) E_{i t}\left(P_{t}\right)}{E_{i t}\left(P_{t+1}\right)}
$$

where $\pi_{t}$ is the real aggregate corporate profit level at time $t, P_{t}$ is the GDP deflator at time $t$, $\tau_{t}$ is the nominal corporate profit level at time $t .{ }^{13} \mathrm{We}$ then use the Gordon growth model to obtain the implied forecast at time $t$ of the market return at time $t+1$ :

$$
E_{i t}\left(r_{t+1}\right)=E_{i t}\left(\frac{\pi_{t+1}}{q_{t}}\right)+\xi_{i t}
$$

where $q_{t}$ is the aggregate market value in the U.S., obtained from the Flow of Funds Accounts of the United States, published by the Federal Reserve, $\xi_{i t}$ is the forecast at time $t$

\footnotetext{
${ }^{11}$ Antoniou et al. (2014) use the first approach suggested by Ellsberg (1961) and measure ambiguity in the cross section of stocks by examining the extent to which analyst earnings forecast accuracy (the likelihood of interest to decision makers that price earnings forecasts) can be predicted from factors such as analyst ability, forecast timeliness, etc.

${ }^{12}$ Output is defined as Gross National Product (GNP) before 1992Q1 and Gross Domestic Product (GDP) thereafter. Similarly, the output deflator is the GNP deflator before 1992Q1 and the GDP deflator thereafter.

${ }^{13}$ Analysts generally produce forecasts for the previous, current and future quarters. See Appendix A in Anderson et al. (2009) for a discussion of issues related to the timing of these forecasts and more details on the procedure that we follow here.
} 
for forecaster $i$ of the gross real growth rate of corporate profits, which as in Anderson et al. (2009), is calculated as the approximate forecast gross growth rate from last quarter to three quarters ahead:

$$
\xi_{i t}=\left(\frac{E_{i t}\left(\tau_{t+3}\right) E_{i t}\left(P_{t-1}\right)}{E_{i t}\left(\tau_{t-1}\right) E_{i t}\left(P_{t+3}\right)}\right)^{1 / 4}
$$

The forecast market return is computed every quarter from 1985 Q1 to 2010 Q4 (i.e., the period for which we have available fund flow data), for all available forecasters. We then follow Anderson et al. (2009) and calculate the beta-weighted dispersion of the forecast market return each quarter across individual forecasters. Define $f_{t}$ as the number of forecasts available in quarter $t$. In each quarter $t$, we rank the $f_{t}$ forecasts from high to low, and assign a weight to the $i^{\text {th }}$ lowest forecast of:

$$
W_{i t}(v)=\frac{i^{v-1}\left(f_{t}+1-i\right)^{v-1}}{\sum_{j=1}^{f_{t}} j^{v-1}\left(f_{t}+1-i\right)^{v-1}}
$$

where the parameter $v$ determines the shape of the weight function: if $v=1$ the forecasts are equally weighted, while higher values of $v$ gives less weight to extreme forecasts. Our quarterly ambiguity measure is given by:

$$
a m b_{t}(v)=\sum_{i=1}^{f_{t}} W_{i t}(v)\left[x_{i t+1 \mid t}-\sum_{j=1}^{f_{t}} W_{j t}(v) x_{j t+1 \mid t}\right]^{2}
$$

In the empirical analysis, we use $v=15.346$, which is the value used by Anderson et al. (2009).

As the SPF data are available on a quarterly basis, and the fund flow data are available only from 1985, we are left with a small sample of 102 data points, which does not allow a powerful test of our hypothesis, especially given the large number of control variables that must be included in the regressions. To circumvent this problem we convert the quarterly ambiguity series into a monthly series using linear interpolation, and conduct the 
analysis using monthly data. ${ }^{14}$ To ensure, however, that this procedure has no implications for our conclusions, in our robustness checks, discussed in Section 4.5, we conduct the analysis using non-interpolated, quarterly data and obtain very similar results.

In our models for the flow analysis we consider the change rather than the level of ambiguity because our hypothesis is that the degree of equity market participation, as measured by total net assets held by mutual funds, is determined by the level of ambiguity, and so fund flows, which represent changes in total net assets, are determined by changes in ambiguity. In equilibrium, for a given level of ambiguity, fund flows will be zero, and so positive (negative) fund flows arise from decreases (increases) in ambiguity.

Panel A in Figure 2 plots the quarterly ambiguity measure and Panel B the changes in the monthly interpolated series. Both measures produce spikes in the mid-1980s to mid-1990s and in the 2000s. Table 2 reports summary statistics for the constructed ambiguity series and for changes in the monthly, interpolated series. Both series are moderately positively skewed and leptokurtic. $^{15}$

[Figure 2 here]

\subsection{Control Variables}

To ensure that the ambiguity measure is not just capturing risk, we include a measure of conditional volatility in the model. In particular, following Andersen et al. (2009), we compute the weighted average of past daily squared excess market returns, using weights on past observations that decline with lag length. The conditional variance is given by:

\footnotetext{
${ }^{14}$ Specifically we calculate monthly ambiguity using quarter $t$ and $t+1$ observations as follows: $a m b_{t, i}=$ $a m b_{t}+\frac{i}{3} *\left(a m b_{t+1}-a m b_{t}\right), i=1,2,3$, where $i$ stands for the $i^{\text {th }}$ month of quarter $t$.

${ }^{15}$ In untabulated analysis, aimed at identifying the factors that affect ambiguity on the macro-level, we regress the level of ambiguity in quarter $t+1$ on the following variables measured at quarter $t$ : an NBER recession dummy, the unemployment rate, changes in consumption, the default spread, the term spread and valueweighted market returns. We find that that the coefficient on the recession dummy is positive and significant at the 5\% level, indicating that ambiguity is higher in recessions. This result is consistent with Anderson et al. (2009, Figure 3 Panel B). These results are available from the authors upon request.
} 


$$
\begin{aligned}
\operatorname{cvar}_{t}(\omega)=s & \sum_{i=1}^{s} l_{i}(\omega)\left(r_{e t, i}-\frac{1}{s} \sum_{j=1}^{s} r_{e t, j}\right)^{2}+2 s \\
& * \sum_{i=1}^{s-1} \sqrt{l_{i}(\omega) l_{i+1}(\omega)} \times\left(r_{e t, i}-\frac{1}{s} \sum_{j=1}^{s} r_{e t, j}\right)\left(r_{e t, i+1}-\frac{1}{s} \sum_{j=1}^{s} r_{e t, j}\right)
\end{aligned}
$$

where $r_{e t, i}$ is the market excess return at $i^{\text {th }}$ lag, which is computed as the daily Center for Research in Security Prices (CRSP) value-weighted index (series VWRETD) return minus the daily return of the three month T-bill, and $l_{i}(\omega)$ indicates the weight attached on the $i^{\text {th }}$ lag. ${ }^{16}$

Figure 3 Panel A plots the monthly conditional variance together with the monthly ambiguity against time, for the period March 1985 to December 2010. It is clear that the two series capture different dimensions of the market, with several periods when ambiguity is high but conditional variance is low, and vice versa. This conclusion can also be seen from Panel B of Figure 3 which presents a scatterplot of ambiguity and risk.

Table 2 reports summary statistics for the conditional variance. As expected, the conditional variance is highly positively skewed and leptokurtic. As with ambiguity, we use the changes in monthly conditional variance in our regression, and Table 2 reports the descriptive statistics for this series. It can be seen that changes in conditional variance are also positively skewed and leptokurtic.

[Figure 3 here]

\footnotetext{
${ }^{16}$ The weight for $i^{\text {th }}$ lag is given by $l_{i}(\omega)=\frac{(s+1-i)^{\omega}}{\sum_{j=1}^{s}(s+1-j)^{\omega}}$, where $s$ is the minimum number of available trading days for the previous 12 months over the entire sample, and the parameter $\omega$ determines the speed at which the weights decline as the lag length increases. In the empirical analysis, we follow Anderson et al. (2009) and use $\omega=14.939$.
} 
There are a number of other factors that have been shown to be important in explaining mutual fund flows, including past fund returns (Ippolito, 1992; Sirri and Tufano, 1998), capital gains (Kamstra et al., 2014), past flows (Ben-Rephael et al., 2011), seasonal effects (Kamstra et al., 2014), advertising expenses (Gallaher, et al., 2006), past market returns (Ben-Rephael, et al., 2012) and savings (Kamstra et al., 2014). Following Kamstra et al (2014) we capture serial correlation in fund flows by including lagged monthly net flows and net exchanges for the past one, two and three months. ${ }^{17}$ We include the personal savings rate from the Bureau of Economic Analysis (series PSAVERT). The data on capital gains and advertising costs is from Kamstra et al. (2014). ${ }^{18} \mathrm{We}$ include the aggregate return of the equity fund group over the previous 12 months to capture return-chasing behaviour and, following Ben-Rephael et al. (2011) and Oh and Parwada (2007), we also include the aggregate market return over the last three months, from $t-3$ to $t-1$. Since transaction costs and liquidity needs have been linked to stock market participation decisions, we include the measure of illiquidity proposed by Amihud (2002) in our regressions, which captures the responsiveness of prices to trading volume. Following Amihud (2002), we calculate for each individual stock $i$ an illiquidity measure in month $t$, and then take the value-weighted average as our measure of market level illiquidity. In our regressions we use the rolling average over the previous three months, from $t-3$ to $t-1$.

Finally, we include dummy variables for the months of November, December, January and February to capture the year-end effect. Table 2 reports summary statistics for the control variables over the period March 1985 to December 2010. Table 3 reports the

\footnotetext{
${ }^{17}$ This lag structure is sufficient to reject the presence of autocorrelation for the majority of our models. For some of the models in in Tables 7 and 9 we add additional lags, and the details are provided in the caption for those tables.

${ }^{18}$ The data on capital gains is from Table 1 of Kamstra et al. (2014), and we would like to thank the authors for kindly providing us with the data on advertising expenses.
} 
correlations between the variables, and we can see that the change in ambiguity is negatively correlated with both net fund flows and net fund exchanges.

[Table 3 here]

The regression for net flows is given by:

$$
\begin{aligned}
\text { netflow }_{t}=a_{0} & +a_{1} \text { Samb }_{t}+a_{2} \Delta \text { cvar }_{t}+a_{3} a d v_{t}+a_{4} \text { Cap }_{t}+a_{5} \text { rfund }_{t-12, t-1} \\
& +a_{6} \text { rmkt }_{t-3, t-1}+a_{7} \text { netflow }_{t-1}+a_{8} \text { netflow } \\
& +a_{9-2} \text { netflow } \text { fl-3 }_{t-3}+a_{10} \text { sav }_{t} \\
& +a_{11} \text { Ilq }_{t-3, t-1}+a_{12} \text { Jan }_{t}+a_{13} \text { Feb }_{t}+a_{14} \text { Nov }_{t}+a_{15} \text { Dec }_{t}+\varepsilon_{t}
\end{aligned}
$$

where $a d v_{t}$ is the aggregate cost of print advertising across all funds divided by the previous year's total advertising cost, $c a p_{t}$ is the capital gains, $s a v_{t}$ is the personal savings rate, $r$ fund $_{t-12, t-1}$ is the aggregate fund return of the previous year, $r m k t_{t-3, t-1}$ is the return on the value-weighted CRSP index over the last 3 months. $I l q_{t-3, t-1}$ is the average market illiquidity from the previous three months, and $\mathrm{Jan}_{t}, \mathrm{Fe} \mathrm{b}_{t}, \mathrm{Nov}_{t}$, and $\mathrm{Dec}_{t}$ are dummy variables that are equal to one in the respective month and zero otherwise.

For net exchanges, we estimate a similar model, but exclude the savings variable and the seasonal dummy variables. The model for net exchanges is therefore given by: netexchange $e_{t}$

$$
\begin{aligned}
& =a_{0}+a_{1} \Delta \text { amb }_{t}+a_{2} \Delta \text { cvar }_{t}+a_{3} \text { adv }_{t}+a_{4} \text { cap }_{t}+a_{5} r \text { fund }_{t-12, t-1} \\
& +a_{6} \text { rmkt } t_{t-3, t-1}+a_{7} \text { netexchang } e_{t-1}+a_{8} \text { netexchang }_{t-2} \\
& +a_{9} \text { netexchange } e_{t-3}+a_{10} \text { Ilq }_{t-3, t-1+\varepsilon_{t}}
\end{aligned}
$$

We estimate models 11 and 12 as a system of equations using the Generalized Method of Moments (GMM) (Hansen, 1982), with heteroscedasticity and autocorrelation consistent standard errors following the procedure from Newey and West $(1987,1994) .{ }^{19}$

\footnotetext{
${ }^{19}$ We use the Bartlett kernel where the autocovariance lag structure is equal to $4 *(N / 100)^{2 / 9}$, where $N$ is the number of observations in the regression. The instruments in each regression model include the full set of independent variables.
} 
According to our hypotheses derived in Section 2, in both the above models the coefficient on changes in ambiguity should be negative and significant, i.e., $\alpha_{1}<0$, indicating that when ambiguity increases, equities experience capital outflows.

\section{Results}

\subsection{Ambiguity and Equity Fund Flows}

Panel A of Table 4 reports the results of estimating equation (11) for net flows for the equity asset class. The coefficient on the change in ambiguity is negative and significant at conventional levels $(-1359.33, p=0.00)$. Therefore, in support of our hypothesis, an increase in ambiguity is associated with a net outflow of capital from equity mutual funds. Changes in conditional variance have a negative but insignificant impact on net flows $(-2.21, p=0.41)$.

Capital gains and market returns are negatively related to flows. The market return result may reflect that investors, after periods of market gains, withdraw capital from equities to lock in their profits. Lagged net fund flows are positive and significant, showing that flows are autocorrelated, consistent with the findings in previous studies (e.g. Kamstra et al., 2014). The savings variable has a significantly positive coefficient, which is consistent with a 'free cash flow' effect on fund flows, and the seasonal dummies are positive and significant, which suggests that there is systematic temporal variation in flows.

[Table 4 here]

Panel B of Table 4 reports the results from estimating equation (12) for net exchanges for the equity asset class. As with net flows, changes in ambiguity are negatively associated with net exchanges, and this relationship is statistically significant $(-502.43, p=0.01)$. Changes in risk also have a negative and significant impact in this model $(-2.12, p=0.02)$. Capital gains are positively related to flows, and similarly to the net flows model lagged exchanges are generally positive and significant. 
These results suggest that an increase in ambiguity has a negative and statistically significant impact on net flows and net exchanges, supporting our hypothesis that increases in ambiguity lead to a reduction in equity market participation. Moreover, while there is a clear link between ambiguity and net fund flows and exchanges, the impact of risk is weaker, as it is significant only when participation is measured with net exchanges. These results are consistent with Anderson et al. (2009), who show that excess market returns have a strong positive association with ambiguity, but a much weaker association with conditional variance, which broadly implies that investors' risk aversion may be dominated by their ambiguity aversion.

To gauge the economic significance of our results, note that the standard deviation of the ambiguity measure is 0.0013 and the average total net assets for equity funds is $\$ 1.9$ trillion; consequently, a one standard deviation change in ambiguity will on average yield a net flow of $\$ 1.7$ billion and a net exchange of $\$ 0.05$ billion.

These findings are relevant for fund managers, who are compensated according to the capital they manage. Since ambiguity can cause volatility to the value of their asset base, it can affect their compensation. Perhaps if managers take measures to reduce perceptions of ambiguity amongst investors, their welfare would be improved. Such measures could also improve the welfare of investors, because they can reduce their transaction costs, which have been shown to be detrimental to their performance (i.e., Barber and Odean, 2000). However, it is not yet clear, how or whether this can be effectively achieved. ${ }^{20}$

\subsection{Ambiguity and Different Equity Styles}

The results in the previous section show that ambiguity adversely affects overall stock market participation. In this section we examine the relationship between ambiguity and fund flows

\footnotetext{
${ }^{20}$ Easley and O'Hara (2010) show that changes in regulation can affect perceptions of ambiguity and portfolio choice.
} 
for the five investment objective categories separately: 'aggressive growth', 'growth', 'sector', 'growth and income' and 'income equity'. ${ }^{21}$ According to the ICI definitions, 'aggressive growth' and 'growth' funds invest in riskier, non-dividend paying stocks with a focus on capital gains, whereas funds in the remaining three categories focus on less risky, dividend-paying stocks (ICI Factbook, 2012). Even though information about holdings is coarse, one could argue that ambiguity will generally be higher for 'aggressive growth' and 'growth' funds, which invest in assets that make "irregular" payments via capital gains, which are difficult to foresee. Conversely, funds that invest more in dividend-payers, which make smoother payments due to the well-known "stickiness" of dividend policy (e.g., Denis and Osobov, 2008), may be perceived as less ambiguous.

The results for net flows are shown in Panel A of Table 5. For brevity, the table reports only the estimated coefficient on the change in ambiguity. For the 'aggressive growth', 'growth' and 'growth and income' categories, the coefficient on the change in ambiguity is negative and highly statistically significant. For the 'income equity' category, the coefficient is negative but not significant, while for the 'sector' category, the coefficient is insignificantly positive. The results for net exchanges are shown in Panel B of Table 5. For the 'aggressive growth', 'growth' and 'income equity', the coefficient on the change in ambiguity is negative and highly statistically significant. For the 'growth and income' category it is negative, and for the 'sector' category it is positive, but in both cases, significant only on the $10 \%$ level.

Overall the results in this section suggest that the flows for all types of funds (apart from 'sector' funds), are negatively related to ambiguity. However, this relationship is much more robust for the 'growth' and 'aggressive growth' funds, where ambiguity is negative and

\footnotetext{
${ }^{21}$ The variables that control for aggregate market characteristics (i.e., risk, returns and liquidity) are the same as those in the baseline model.
} 
highly significant for both the net flows and net exchanges models. This finding suggests that such funds, which tend to pursue capital gains, are perceived as more ambiguous by the market, and thus eschewed more strongly in periods of high ambiguity.

[Table 5 here]

\subsection{Ambiguity and non-Equity Fund Flows}

In this section we examine the relationship between changes in ambiguity and flows in funds that invest in non-equity asset classes, namely hybrid, government and corporate fixed income and money market.

Table 6 reports the estimated coefficient on the change in ambiguity from the net flows (Panel A) and net exchanges (Panel B) model. For both the net flows and net exchanges, the coefficient on ambiguity is negative and generally significant for all fund families, except for the money market fund family where the coefficient is positive. Thus, as ambiguity increases, investors withdraw capital from both equity and fixed income funds and reinvest, at least partially, in money market funds, which, according to the ICI Factbook (2012), invest in low risk, high-grade assets that receive full principal and interest within 90 days on average. However, the results related to net exchanges from government fixed income funds and money market funds should be treated with caution because in those models the null hypothesis of no autocorrelation in the residuals is rejected at the $5 \%$ confidence level.

[Table 6 here]

\subsection{Ambiguity and Short Selling}

Our analysis thus far relies on analysing stock participation via mutual funds, which are generally restricted from taking short positions. It is possible that our ambiguity measure is only picking up pessimism in beliefs and so when this measure is high, pessimistic SEU agents (not ambiguity averse) withdraw their long positions (i.e., withdraw their money from 
mutual funds), and initiate short positions on their own, leaving overall market participation unchanged. Although this explanation is unlikely given that individual investors are reluctant to sell short (Barber and Odean, 2008), we conduct some analysis in this section to rule it out. In particular, we examine the relationship between aggregate short selling activities in the market and our ambiguity proxy. Using data from COMPUSTAT for the period 1985-2010 we calculate the aggregate value-weighted short-ratio (the number of shares held short at time $t$ divided by the number of shares outstanding at time $t$ ), and then estimate an OLS model, regressing the change in ambiguity on the change in this variable. In unreported analysis, available upon request, we obtain a negative coefficient that is marginally statistically significant (Newey-West adjusted $p$-value $<0.07$ ). This means that increases in ambiguity reduce short positions in the stock market, which in turn implies that ambiguity is negatively related to overall market participation, as predicted by the theoretical literature (e.g., Dow and Werlang, 1992; Epstein and Schneider, 2010).

\subsection{Robustness}

As discussed in the methodology section, we use linear interpolation for the ambiguity measure to obtain monthly estimates and hence increase the power of our tests. In this section we estimate the models given by (11) and (12) using non-interpolated, quarterly data. We continue to use Newey and West $(1987,1994)$ heteroscedasticity and autocorrelation consistent standard errors, and estimate (11) and (12) as a system of equations for the different fund families using GMM.

Net flows and exchanges are calculated on a quarterly basis. The changes in ambiguity and conditional variance are equal to $\Delta Q c v a r_{t}=c v a r_{t}-c v a r_{t-3}$ and $\Delta Q a m b_{t}=$ $a m b_{t}-a m b_{t-3}$, respectively. Quarterly capital gains, savings and advertising costs are equal to the sum of the monthly values over each quarter. Lagged market return, illiquidity premium and fund return are defined as previously. 
The results for these quarterly regressions are shown in Table 7. Even though the number of observations in these models is reduced threefold, we still find that increases in ambiguity are negatively and significantly related to both fund flows (Panel A: $-1483.41, p$ value $=0.00$ ) and fund exchanges (Panel B:-684.93, $p$-value $=0.00)$. In this model the risk variable is also negative and statistically significant for both the net flows $(-38.63, p$ value $=0.01)$ and net exchanges models $(-28.95, p$-value $=0.00)$. The other relationships are generally similar as those in Table 4, with the exception of the past market and fund returns variables, which have a positive and significant effect for both the net flows and net exchanges models. ${ }^{22}$

\section{[Table 7 here]}

A concern with the ambiguity index is that it may be related to time-varying "sentiment" toward the stock market, which has been shown to affect equity investments through mutual funds (Ben-Rephael et al., 2012). To control for this possibility we estimate an expanded version of our baseline model, controlling for the sentiment index of Baker and Wurgler (2006), and the median forecast from the SPF data. Both of these variables help to capture investors' outlook toward the stock market, and therefore ensure that our findings are not merely reflecting the effects of investor sentiment on stock market participation.

The results from estimating this expanded model are shown in Table 8 . In this specification the ambiguity variable remains negative and significant, for both the net flows $(-1555.42, p$-value $=0.00)$ and net exchanges model $(-542.09, p$-value $=0.01)$. The sentiment variables are insignificant for both the net flows and net exchanges models. Overall the results in Table 8 suggest that our baseline findings are not just capturing the effect of investor sentiment toward the stock market.

[Table 8 here]

\footnotetext{
${ }^{22}$ This may reflect that flows calculated over longer periods are chasing market and fund returns.
} 
We continue to repeat the analysis in Table 4 using four different specifications for risk to ensure that our findings are robust. The first alternative risk measure we use is realized volatility, calculated as the sum of daily squared market returns, using the CRSP valueweighted return series. In addition, we use two GARCH models to forecast market return volatility. The first is a GARCH-M model, that forecasts volatility conditional on it past realizations, and the second is a GJR GARCH model, which allows for asymmetric temporal relationships in volatility during upturn and downturn markets due to leverage effects. We follow Glosten, Jaganathan and Runkle (1993) to specify these models, which we estimate in the full sample, and then use the estimated coefficients to produce forecasts for volatility in month $t+1$, which we use to define the independent risk variables in our regressions. Our last variable is the CBOE market volatility index (series VXO), ${ }^{23}$ which captures expectations about future volatility of aggregate market returns. Due to data availability on the volatility index the time period for this test is slightly shorter, from 1986-2010. We estimate the model from Table 4 for both net flows and net exchanges, replacing our original risk measure with these alternative definitions.

The results are shown in Table 9. For brevity, we report results only for the coefficients on the change in ambiguity and risk. As seen in Table 9, the risk specifications have the expected negative sign, and are generally statistically significant, consistent with our previous findings. The GARCH models seem to perform better than the realized variance model, which suggests that conditional estimates of volatility produce a better model for perceived risk. The risk variable is also negative and highly statistically significant when it is

\footnotetext{
${ }^{23}$ The VXO and VIX versions of the volatility index series are interchangeable, with a correlation of $99 \%$. We use the VXO series in our analysis because it is available for a longer time period. Our results are robust however to a specification of the volatility index based on both the VXO and VIX following the procedure in Whaley (2009, footnote 9). These results are available from the authors upon request.
} 
measured using the VXO index. ${ }^{24}$ Importantly, ambiguity continues to exert a negative and significant effect on both net flows and net exchanges for all models, regardless of the volatility variable used, which indicates that our findings are robust to different risk specifications.

[Table 9 here]

\section{Ambiguity and the Proportion of Households that Invest in Stocks}

In this section we examine whether ambiguity affects the proportion of households that invest in stocks. To answer this question we use data from the Survey of Consumer Finances (SCF), obtained from the Board of Governors of the Federal Reserve. This survey is conducted every three years since 1989, and gathers demographic and financial information from a large number of different households. In our sample we include data from eight different surveys, ending in 2010. This survey has been used extensively in academic research (e.g., Malmendier and Nagel, 2011).

We estimate a logistic model, where the dependent variable, stock $k_{i, t}$, is a binary indicator, set to 1 if individual $i$ from cohort $t$ owns equities, either directly or via mutual funds, and zero otherwise. We include the following market-wide variables: The variable of interest $a m b_{t-1, t-3}$ reflects the average ambiguity during the three years before year $t$ when the survey is conducted and is calculated as per Equation (9). Since our ambiguity variable only varies between surveys, this model is essentially testing whether increases in ambiguity across time result in a reduction in participation rates across the different cohorts. Market risk, $v_{t o l} l_{t-1-3}$ is the corresponding realized volatility based on the return of the CRSP valueweighted index over the same period. In addition, following the evidence in $\mathrm{Li}$ and $\mathrm{Yu}(2012)$

\footnotetext{
${ }^{24}$ A caveat worth noting is that some authors have argued that the volatility index does not reflect an unbiased forecast of future volatility, but rather is an index of irrational market sentiment (Baker and Wurgler, 2007; Kaplanski and Levy, 2010). Therefore, the finding that increases in the VXO lead to decreases in equity investments potentially conflates both the effects of "rational" risk aversion and "irrational" biases in beliefs.
} 
that investors' stock investment decisions are anchored to recent trends, we include in the models the variable $A n c h_{t}$ calculated as the average Dow index price of the last year divided by the historical high price of the Dow index. Li and Yu (2012) show that the higher this ratio, the higher the valuation of the market, because investors are more willing to invest since the market valuation is close to the historical high.

In our model, we also include the following individual-specific control variables: income $_{i, t}$ (the natural logarithm of income in chained 2010 dollars), risk attitude $e_{i, t}$ (three dummies which flag whether the individual is willing to capture average, above average or substantial financial risk), ${ }^{25}$ race $_{i, t}$ (a dummy equal to 1 if the household is declared as white

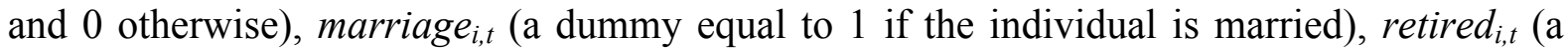
dummy equal to 1 if the individual is retired), age $e_{i, t}$ (in years) and education ${ }_{i, t}$ (a dummy equal to 1 if the individual has a college degree). ${ }^{26}$

The response probability modelled is that the household owns equities conditional on the predictors in the vector $\boldsymbol{X}$ outlined above, $p=\operatorname{Pr}($ Stock $=1 \mid \boldsymbol{X})$, and the linear logistic model is of the form:

$$
\log \left(\frac{p}{1-p}\right)=\mathrm{a}+\mathrm{b}^{\prime} \boldsymbol{X}
$$

where $a$ is the intercept parameter and $b$ is a vector of slope parameters, estimated with maximum likelihood. We adjust standard errors for multiple imputations following the method of Rubin (1987). According to our hypotheses, the coefficient on ambiguity should be negative.

\footnotetext{
${ }^{25}$ In each survey the household is asked to choose one of the following four options: 1) Not willing to take any financial risks, 2) Take average financial risks expecting to earn average returns, 3) Take above average financial risks expecting to earn above average returns, and 4) Take substantial financial risks expecting to earn substantial returns. We create three dummies, which take the value of 1 if the individual has chosen option 2, 3 and 4 , respectively and 0 otherwise.

${ }^{26}$ These variables have been chosen because they can affect portfolio decisions. For example, the effects of marital status and race are shown in Barber and Odean (2002) and Kumar (2009), respectively. Moreover, older and retired people may have different preferences compared to their younger counterparts who are still in employment. Educated people may be in a better position to tap into financial markets.
} 
The results are shown in Table 10. The control variables have the expected signs: The participation rate drops with market volatility, and increases with the anchoring variable. In addition, we find the less risk averse the individual, the larger the probability she invests in equities. Moreover, individuals who hold a college degree, who are married and are of white origin are more likely to participate. Finally, the probability of participation rises with both income and age. In terms of the market wide variables, the probability of participation increases with market risk and increases with market trends.

As predicted by the theoretical literature, and in line with the analysis in the previous section of the paper, we find that, controlling for various firm and market level variables, ambiguity exerts a significant negative influence on the probability that a household invests in equities. ${ }^{27}$ Using marginal effects, we estimate that a one standard deviation increase of ambiguity reduces the probability of participation by $4.66 \%(p<0.01)$.

[Table 10 here]

\section{Conclusion}

The theoretical literature that analyses portfolio choice in the context of ambiguity robustly predicts that stock market participation is negatively affected by stock market ambiguity. In this paper we empirically test this prediction. We measure stock market participation in two ways: using capital flows in and out of U.S. equity mutual funds using data from the Investment Company Institute (ICI), and with the proportion of households that invest in equities, estimated using data from the Survey of Consumer Finances (SCF).

Our measure of market-wide ambiguity is based on a recent study by Anderson et al. (2009) and reflects the dispersion in analysts' implied forecasts about market returns. This

\footnotetext{
${ }^{27}$ This result is robust if we eliminate households with reported income of less than 1000 dollars, and households with a head who is younger than 24 or older than 75 .
} 
measure closely corresponds to the definitions of ambiguity provided by Ellsberg (1961), and is in line with various applications of ambiguity in finance (e.g. Hansen and Sargent, 2001; Ulrich, 2013; Drechsler, 2012; Shi, 2013).

Our results show that increases in ambiguity are significantly and negatively related to equity fund flows. We find that this relationship is more pronounced for funds classed as 'aggressive growth' or 'growth', which tend to invest in more ambiguous assets. The results using the SCF analysis data corroborate these findings. Controlling for various household and market level factors, we find that higher ambiguity leads to a reduction in the probability that the average household owns equities. Overall our findings are supportive of the theoretical prediction, that stock market participation is negatively related to ambiguity. 


\section{References}

Amihud. Y., 2002, 'Illiquidity and stock returns: cross-section and time-series effects', Journal of Financial Markets, 7, 31-56.

Anderson, E., Ghysels, E., and Juergens, J., 2009, 'The impact of risk and uncertainty on expected returns', Journal of Financial Economics, 94, 233-263.

Antoniou, C., Galariotis, E.C., and Read, D., 2014, 'Ambiguity aversion, company size and the pricing of earnings forecasts', European Financial Management, 20, 633-651.

Antoniou, C., Doukas, J.A., and Subrahmanyam, A., 2014, 'Investor sentiment, beta, and the cost of equity capital', Management Science, forthcoming.

Baker, M., and Wurgler, J., 2006, 'Investor sentiment and the cross-section of stock returns', Journal of Finance 61, 1645-1680.

Baker, M., and Wurgler, J., 2007, 'Investor sentiment in the stock market', Journal of Economic Perspectives, 21, 129-152.

Barber, M., and Odean, T., 2000, 'Trading is hazardous to your wealth: The common stock investment performance of individual investors', Journal of Finance, 55, 773-806.

Barber, M., and Odean, T., 2002, 'Online investors: Do the slow die first?', Review of Financial Studies, 15, 455-489.

Barber, B., and Odean, T., 2008, 'All that glitters: The effect of attention and news on the buying behaviour of individual and institutional investors', Review of Financial Studies, 21, 785-818.

Ben-Rephael, Kandel, A.,S., and Wohl, A., 2012, 'Measuring investor sentiment with mutual fund flows', Journal of Financial Economics, 104, 363-382.

Ben-Rephael, Kandel, A.,S., and Wohl, A., 2011, 'The price pressure of aggregate mutual fund flows', Journal of Financial and Quantitative Analysis, 46, 585-603.

Brenner, M., and Izhakian, Y., 2011, 'Asset pricing and ambiguity: Empirical Evidence', working paper, New York University.

Brenner, M., and Izhakian, Y., 2012, 'Pricing systematic ambiguity in capital markets', working paper, New York University.

Camerer, C., and Weber, M., 1992, 'Recent developments in modeling preferences: Uncertainty and ambiguity'. Journal of Risk and Uncertainty, 5, 325-370.

Cao, H., Wang. T., and Zhang, H., 2005, 'Model uncertainty, limited market participation and asset prices', Review of Financial Studies, 18, 1219-1251.

Cooper, M.J., Gulen, H., and Rau, R.P., 2005, 'Changing names with style: mutual fund name changes and their effects on fund flows.' Journal of Finance, 60, 2825-2858.

Collard, F., Mukerji, S., Sheppard, K., and Tallon, J., 2011, 'Ambiguity and the historical equity premium', working paper, University of Oxford.

Denis, D., J., and Osobov, L., 2008, 'Why do firms pay dividends? International evidence on the determinants of dividend policy', Journal of Financial Economics, 89, 62-82.

Dimmock, S., Kouwenberg, R., Mitchell, O., and Peijnenburg, K., 2013, 'Ambiguity Aversion and Household Portfolio Choice: Empirical Evidence', working paper, the National Bureau of Economic Research.

Dow, J., and Werlang, S., 1992, 'Ambiguity aversion, risk aversion, and the optimal choice of portfolio', Econometrica, 60, 197-204. 
Drechsler, I., 2012, 'Uncertainty, time-varying fear, and asset prices', Journal of Finance, forthcoming.

Einhorn, J. H. and Hogarth, M. R., 1985, 'Ambiguity and uncertainty in probabilistic inference', Psychological Review, 92, 433-462.

Epstein, L. G., and Schneider, M.., 2008, 'Ambiguity, information quality, and asset pricing', Journal of Finance, 63, 197-228.

Epstein, L. G., and Schneider, M., 2010, 'Ambiguity and asset market', Annual Review of Financial Economics, 2, 315-346.

Easley, D., and O'Hara, M., 2009, 'Ambiguity and nonparticipation: the role of regulation', Review of Financial Studies, 22, 1817-43.

Ellsberg, D., 1961, 'Risk, ambiguity, and the Savage axioms', Quarterly Journal of Economics, $75,643-669$.

Frisch, D. And Baron, J., 1988, 'Ambiguity and Rationality', Journal of Behavioral Decision Making, 1, 149-157.

Gärdenfors, P. and Sahlin, N. E., 1982, 'Unreliable Probabilities, risk taking, and decision making', Synthese, 361-386.

Gärdenfors, P. and Sahlin, N. E., 1983, 'Decision Making with Unreliable Probabilities', British Journal of Mathematical and Statistical Psychology, 36, 1983, 240-251.

Gallaher, S., Kaniel, R., and Starks, L., 2006, 'Mutual funds and advertising, mimeo', working paper, University of Texas at Austin.

Garlappi, L., Uppal, R., and Wang, T., 2007, 'Portfolio selection with parameter and model uncertainty: A multi-prior approach', Review of Financial Studies, 20, 42-81.

Gilboa, I., and Schmeidler, D., 1989, 'Maxmin expected utility with non-unique prior', Journal of Mathematical Economics, 18, 141-153.

Glosten, L., Jagannathan, R., and Runkle, D. E., 1993, 'On the relation between the expected value and the volatility of the nominal excess return on stocks', Journal of Finance, 48, 1779-1801.

Grinblatt, M., Keloharjub,M., and Linnainmaa, J., 2012, 'IQ, trading behavior, and performance,' Journal of Financial Economics, 104, 339-362.

Guidolin, M., and Rinaldi, F., 2013, 'Ambiguity in asset pricing and portfolio choice: a review of the literature', Theory and Decision, 74, 183-217.

Guiso, L., Sapienza, P., and Zingales, L., 2008, 'Social Capital as Good Culture,' Economics Working Papers, European University Institute.

Hansen, L., 1982, 'Large Sample Properties of Generalized Method of Moments Estimators,'Econometrica, 50,1029-1054.

Hansen, L. P., and Sargent, J., 2001, 'Robust Control and Model Uncertainty', American Economic Review, 91, 60-66.

Hong, H., Kubik, J. D., and Stein, J. C., 2004, 'Social interaction and stock-market participation', Journal of Finance, 59, 137-163.

Hribar, P., and McInnis, J. 2012, 'Investor sentiment and analysts' earnings forecast errors', Management Science 58, 293-307.

Hsu, M., Bhatt, M., Adolphs, R., Tranel, D., and Camerer, C. F., 2005, 'Neural systems responding to degrees of uncertainty in human decision-making', Science, 310, 16801683. 
Investment Company Institute, 2012, Investment Company Fact Book: A Review of Trends and Activity in the U.S. Investment Company Industry, 52nd Edition.

Investment Company Institute, 2003, Mutual Fund Fact Book: A Guide to Trends and Statistics in the Mutual Fund Industry, 43rd Edition.

Ippolito, R.A., 1992, 'Consumer reaction to measures of poor quality: evidence from the mutual fund industry', Journal of Law and Economics, 35, 45-70.

Ivkovich. Z., and Weisbenner, S., 2009, 'Individual Investor Mutual-Fund Flows.' Journal of Financial Economics, 92, 223-237.

Jain, C., and Wu, S., 2000, 'Truth in mutual fund advertising: evidence of future performance and fund flows', Journal of Finance, 55, 937-958.

Kacperczyk, M., and Seru, A., 2007, 'Fund manager use of public information: new evidence on managerial skills', Journal of Finance 62, 485-528.

Kamstra, M.J., Kramer, L.A., Levi, M.D., and Wermers, R., 2014, 'Seasonal asset allocation: evidence from mutual fund flows', working paper, University of Toronto.

Kaplanski, G., and Levy, H., 2010, 'Sentiment and stock prices: the case of aviation disasters', Journal of Financial Economics, 95, 174-201.

Keynes, J., 1921, A Treatise on Probability, Cornell University Library, New York.

Kelsey, D., Kozhan, R., and Pang, W., 2008, 'Asymmetric momentum effects under uncertainty', Review of Finance, 15, 603-631.

Keren, G. B., and Gerritsen, L. E. M., 1999, 'On the robustness and possible accounts for ambiguity aversion', Acta Psychologica, 103, 149-172.

Knight, F.H., 1921, Risk, Uncertainty and Profit, Houghton Mifflin Company, Boston, MA.

Kumar, A., 2009, 'Who Gambles in the Stock Market?,' The Journal of Finance, 64, 18891933.

Levy I., Snell, J., Nelson, A. J., Rustichini, A., and Glimcher, P., 2010, 'The neural representation of subjective value under risk and ambiguity', Journal of Neurophysiology, 103, 1036-1047.

Li, J., Yu, J., 2012, 'Investor attention, psychological anchors, and stock return predictability', Journal of Financial Economics, 104, 401-419.

Maenhout, P., 2004, 'Robust portfolio rules and asset pricing', Review of Financial Studies, 17, 951-983

Malmendier, U., Nagel, S., 2009, 'Depression Babies: Do Macroeconomic Experiences Affect Risk-Taking?,' NBER Working Papers 14813, National Bureau of Economic Research,

Mukerji, S., and Tallon, J.M., 2001, 'Ambiguity aversion and incompleteness of financial markets,' Review of Economic Studies, 68, 883-904.

Newey, W. K. and West, K. D., 1987, 'A simple positive semi-definite heteroscedasticity and autocorrelation consistent covariance matrix', Econometrica, 55, 703-708.

Newey, W.K. and West, K. D., 1994, 'Automatic lag selection in covariance matrix estimation', Review of Economic Studies, 61, 631-653.

Oh, N., and Parwada, J., 2007, 'Relations between Mutual Fund Flows and Stock Market Returns in Korea', Journal of International Financial Markets, Institutions \& Money 17 (2), 140-151. 
Rubin, D., 1987, Multiple Imputation for Non-response in Surveys, New York: John Wiley \& Sons.

Shi, Z., 2013, Time-varying ambiguity and asset pricing puzzles', Working paper, Penn State University.

Sirri, E., and Tufano, P., 1998, 'Costly search and mutual fund flows', Journal of Finance, $53,1589-1622$.

Ulrich, M., 2013, 'Inflation ambiguity and the term structure of U.S. government bonds', Journal of Monetary Economics, 60, 295-309.

Whaley, R. E., 2009, 'Understanding the VIX', Journal of Portfolio Management, 35, 98-105. 
Figure 1: Net Flows and Net Exchanges for the Equity Asset Class.

The figure reports the monthly net flows and net exchanges for the equity asset class, which comprises funds within the 'aggressive growth', 'growth', 'sector', 'growth and income', and 'income equity' investment objective categories. The data is from ICI and covers the period March 1985 to December 2010. Net flows (Panel A) and net exchanges (Panel B) are calculated according to Equations (3) and (4).

\section{Panel A. Net flows}

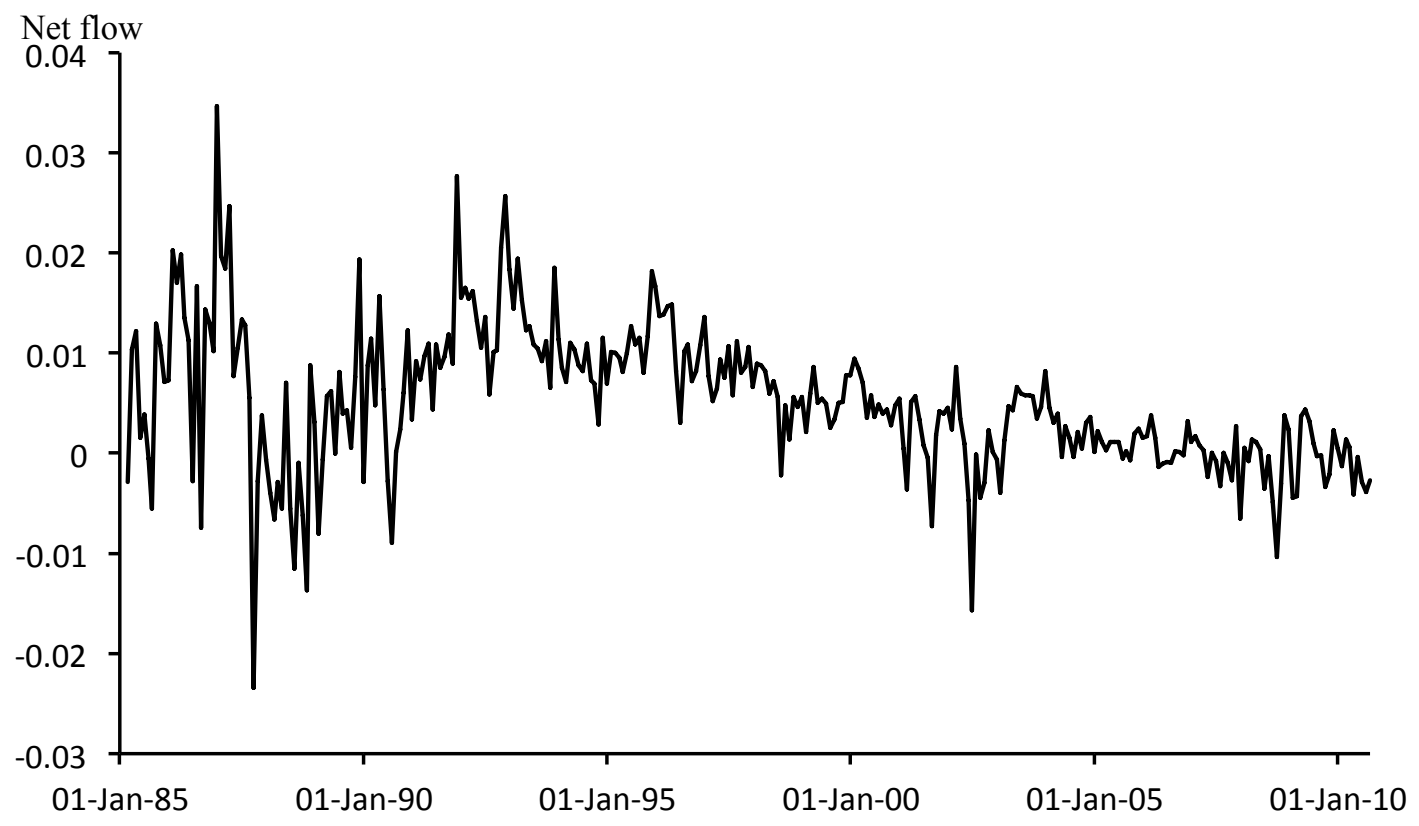

Panel B. Net exchanges

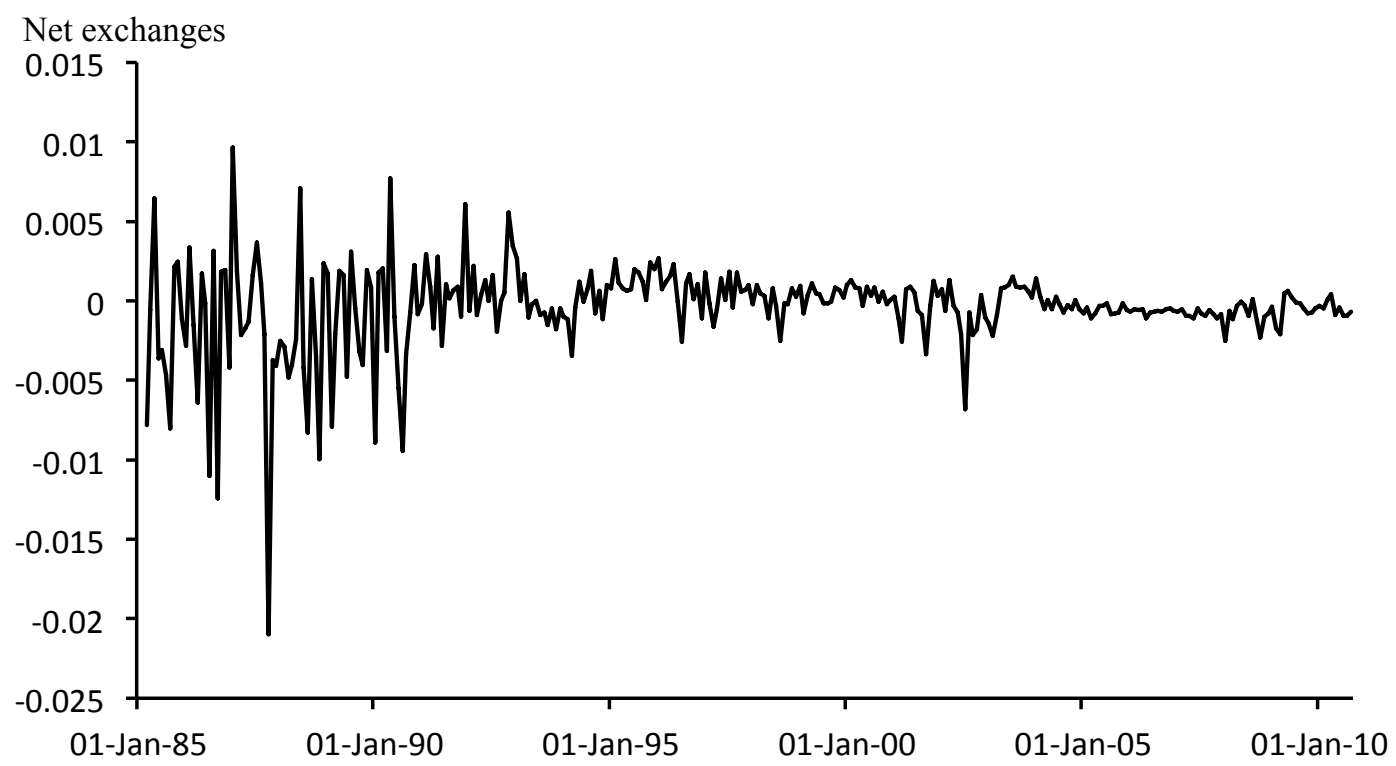


Figure 2: Ambiguity

The figure reports quarterly ambiguity (Panel A) and the change in monthly ambiguity (Panel B), from 1985 to 2010. The ambiguity measure reflects the dispersion in forecasts for market returns, obtained using data from the Survey of Professional Forecasters. To calculate this measure we follow Anderson et al. (2009), and use forecasts of aggregate output, the output deflator, and corporate profits after taxes, which we combine as per Equation (9) with $v=15.346$. Monthly ambiguity is computed from the quarterly measure by linear interpolation. Both series are scaled by 100 .

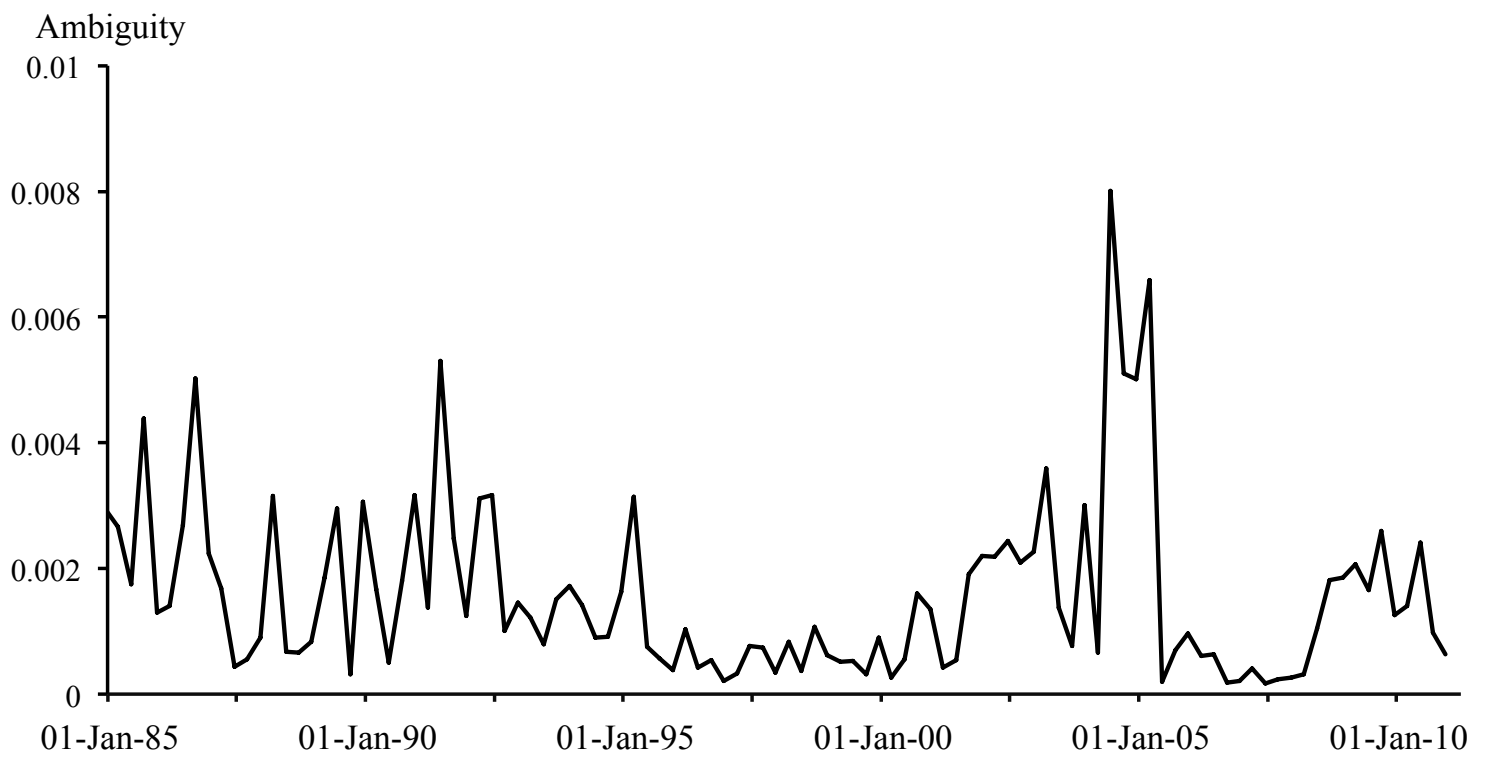

Panel B. Changes in monthly interpolated ambiguity

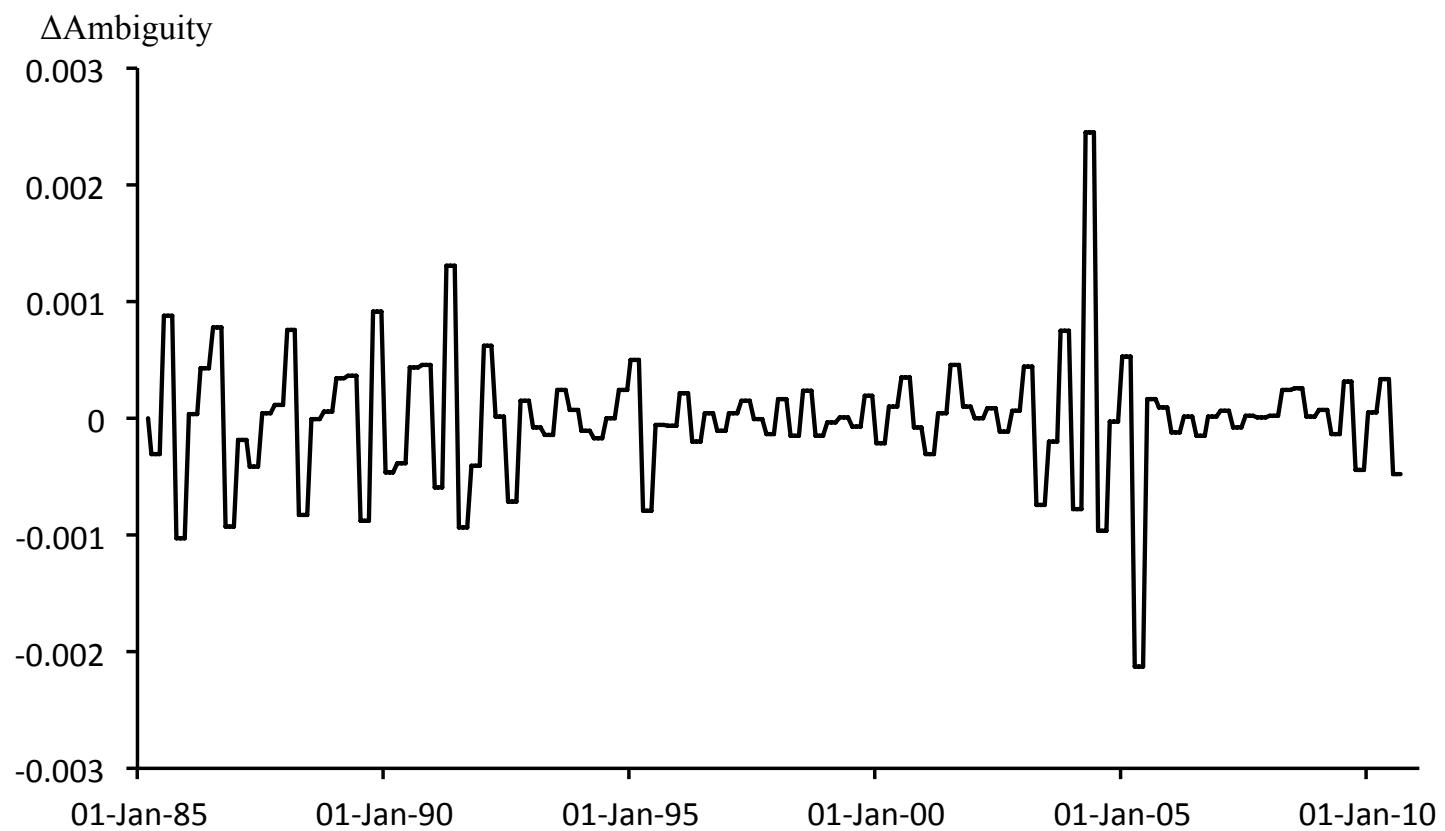




\section{Figure 3: Ambiguity and Risk over Time.}

The figure reports monthly ambiguity (dashed line) and conditional variance of market returns (solid line) from March 1985 to December 2010. Conditional variance is calculated following Anderson et al. (2009) using data from CRSP. In panel B we produce a scatterplot of ambiguity and risk.

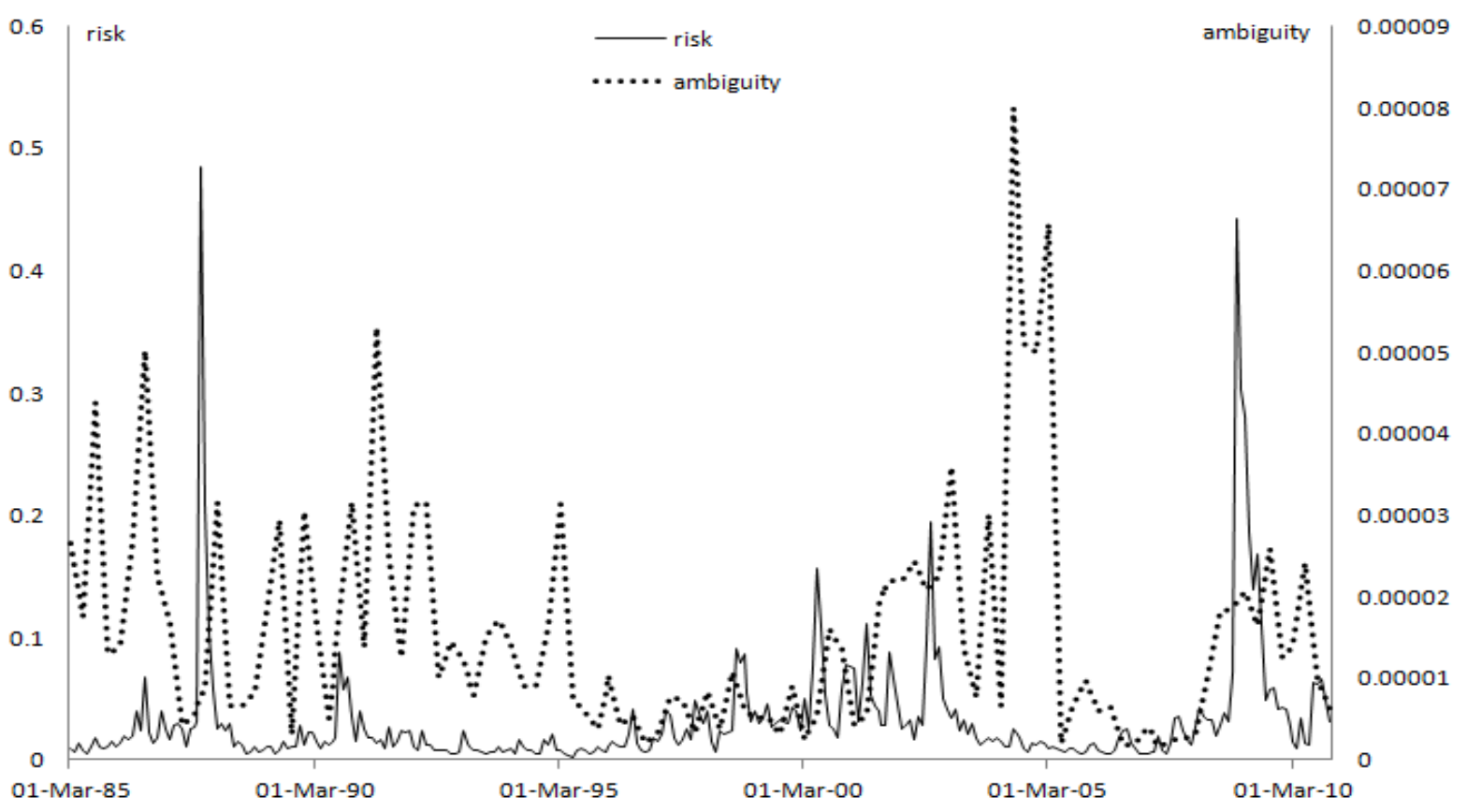

Figure 3: Continued.

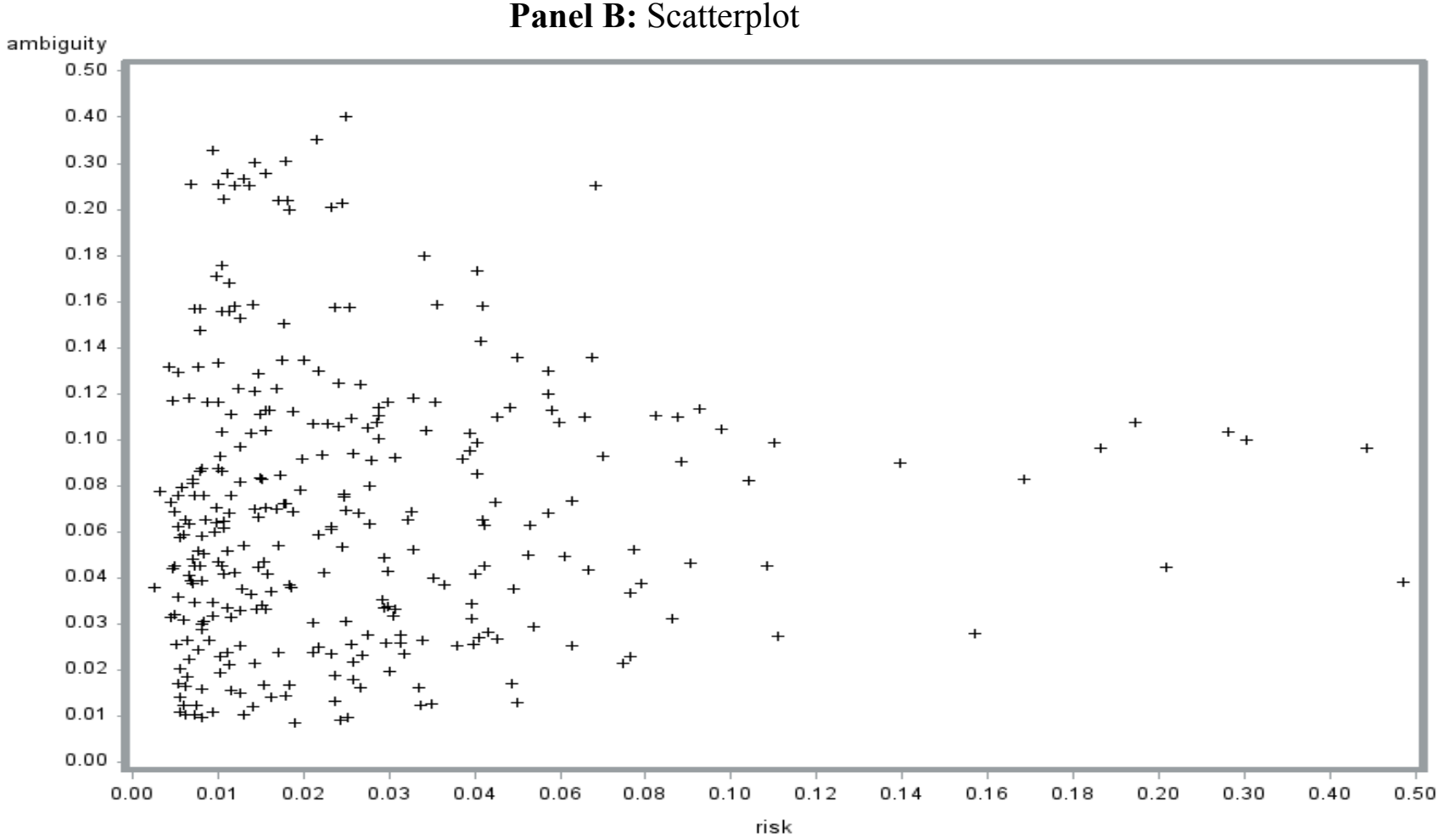


Table 1: Classification of Mutual Funds

The table reports the categorisation of the ICI fund investment objective categories by asset class, based on Kamstra et al. (2014).

\begin{tabular}{ll}
\hline Fund Investment Objective & Fund Asset Class \\
\hline Aggressive Growth & Equity \\
Growth & Equity \\
Sector & Equity \\
Growth and Income & Equity \\
Income Equity & Equity \\
Asset Allocation & Hybrid \\
Balanced & Hybrid \\
Flexible Portfolio & Hybrid \\
Income Mixed & Hybrid \\
Corporate - General & Corporate Fixed Income \\
Corporate - Intermediate & Corporate Fixed Income \\
Corporate - Short Term & Corporate Fixed Income \\
High Yield & Corporate Fixed Income \\
Strategic Income & Corporate Fixed Income \\
Government Bond - General & Government Fixed Income \\
Government Bond - Intermediate & Government Fixed Income \\
Government Bond - Short Term & Government Fixed Income \\
Mortgage Backed & Government Fixed Income \\
State Municipal Bond - General & Government Fixed Income \\
State Municipal Bond - Short Term & Government Fixed Income \\
National Municipal Bond - General & Government Fixed Income \\
National Municipal Bond - Short Term & Government Fixed Income \\
Taxable Money Market - Government & Money Market \\
\hline
\end{tabular}


Table 2: Summary Statistics

The table reports summary statistics for the various variables for the period March 1985 to December 2010. The ambiguity measure, $a m b_{t}$ reflects the dispersion in forecasts for market returns, calculated using data from the Survey of Professional Forecasters. To calculate this measure we follow Anderson, et al. (2009), and use forecasts of aggregate output, the output deflator, and corporate profits after taxes, which we combine as per Equation (9) with $v=15.346$ multiplied by 100. cvar $_{t}$ is conditional variance calculated according to Anderson et al (2009). $\Delta a m b_{t}$ and $\Delta c v a r_{t}$ are the change in ambiguity and risk, respectively, $a d v_{t}$ is the aggregate cost of print advertising across all funds, divided by the previous year's total advertising cost, cap $_{t}$ is the capital gains in month $t$, from Kamstra et al. (2014, Table 1). $s a v_{t}$ is the personal savings rate taken from the Bureau of Economic Analysis (series PSAVERT), $r$ fund $_{t-12, t-1}$ is the aggregate return of equity funds over the previous 12 months, $r m k t_{t-3, t-1}$ is the return on the CRSP value-weighted index (series VWRETD) over the last 3 months and $I l q_{t-3, t-1}$ is the Amihud liquidity measure aggregated on value-weighted basis and averaged for the previous three months.

\begin{tabular}{lcccccc}
\hline & Mean & Std & Skew & Kurt & Max & Min \\
\hline Net exchanges & 0.000 & 0.003 & -2.149 & 13.960 & 0.010 & -0.021 \\
Net flow & 0.005 & 0.007 & 0.242 & 1.692 & 0.035 & -0.023 \\
amb $_{\boldsymbol{t}}$ & 0.002 & 0.001 & 1.800 & 4.206 & 0.008 & 0.000 \\
Samb $_{\boldsymbol{t}}$ & 0.000 & 0.001 & 0.296 & 5.993 & 0.002 & -0.002 \\
cvar $_{\boldsymbol{t}}$ & 0.032 & 0.051 & 5.496 & 38.664 & 0.485 & 0.003 \\
ccvar $_{\boldsymbol{t}}$ & 0.000 & 0.043 & 4.827 & 61.813 & 0.454 & -0.276 \\
rfund $_{t-12, t-1}$ & 0.167 & 0.218 & -0.966 & 0.868 & 0.583 & -0.580 \\
adv $_{t}$ & 0.086 & 0.012 & 0.811 & 5.933 & 0.144 & 0.038 \\
cap $_{t}$ & 8.408 & 19.446 & 2.938 & 6.827 & 72.000 & 0.900 \\
sav $_{t}$ & 0.049 & 0.019 & 0.007 & -0.801 & 0.103 & 0.009 \\
rmkt $_{t-3, t-1}$ & 0.028 & 0.085 & -1.076 & 2.855 & 0.264 & -0.367 \\
Ilq $_{t-3, t-1}$ & 0.000 & 0.000 & 3.015 & 14.236 & 0.000 & 0.000 \\
\hline
\end{tabular}


Table 3: Correlations

The table reports the correlation matrix for the various variables for the period March 1985 to December 2010, defined as in Table 2.

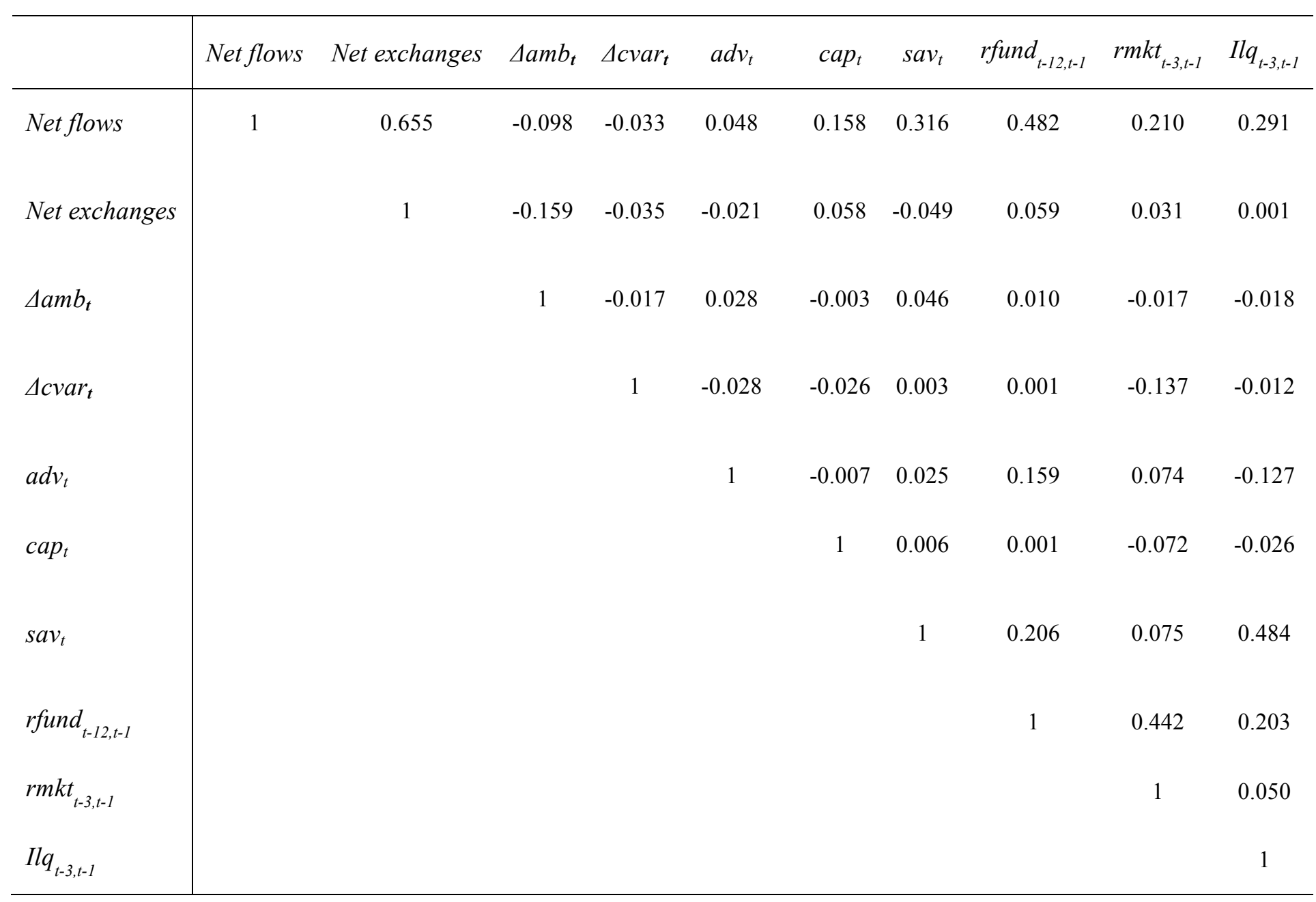




\section{Table 4: Ambiguity and Equity Fund Flows and Exchanges}

The table reports the results of estimating the net flows model (Panel A) and the net exchanges model (Panel B) for the equity asset class, for the period March 1985 to December 2010. The variables are defined as in Table 2. $P_{\mathrm{A}}$ is the $p$-value from a Breusch-Godfrey autocorrelation test. To perform the test we first jointly estimate the models shown in equations 11 and 12 for all 5 fund families using GMM, and then use the residuals to test whether they exhibit autocorrelation up to the sixth lag. $P_{\mathrm{O}}$ is the $p$-value from a test of overidentifying restrictions. Standard errors are adjusted for autocorrelation and heteroscedasticity using the Newey-West (1994) estimator. The classification of mutual funds is based on Kamstra et.al (2014), and is shown in Table 1. All coefficients and standard errors are multiplied by 1000.

\begin{tabular}{|c|c|c|c|c|}
\hline \multicolumn{5}{|c|}{ Panel A. Net flows } \\
\hline & Estimate & Std Err & $t$ statistic & prob $>t$ \\
\hline Intercept & -0.75 & 1.08 & -0.69 & 0.49 \\
\hline$\Delta a m b_{t}$ & -1359.33 & 323.70 & -4.21 & 0.00 \\
\hline$\Delta c v r_{t}$ & -2.21 & 2.69 & -0.82 & 0.41 \\
\hline$a d v_{t}$ & 2.03 & 10.80 & 0.19 & 0.85 \\
\hline $\mathrm{cap}_{t}$ & -0.46 & 0.21 & -2.23 & 0.03 \\
\hline rfund $_{t-12, t-1}$ & 0.57 & 0.53 & 1.09 & 0.28 \\
\hline$r m k t_{t-3, t-1}$ & -3.50 & 1.72 & -2.04 & 0.04 \\
\hline Net flow ${ }_{t-1}$ & 357.39 & 40.70 & 8.78 & 0.00 \\
\hline Net flow ${ }_{t-2}$ & 145.02 & 73.20 & 1.98 & 0.05 \\
\hline Net flow ${ }_{t-3}$ & 303.99 & 32.10 & 9.46 & 0.00 \\
\hline$s a v_{t}$ & 30.48 & 10.50 & 2.89 & 0.00 \\
\hline$I l q_{t-3, t-1}$ & 14884.77 & 20389.20 & 0.73 & 0.47 \\
\hline $\mathrm{Jan}_{t}$ & 1.20 & 0.63 & 1.89 & 0.06 \\
\hline $\mathrm{Feb}_{t}$ & 0.00 & 0.56 & 0.00 & 1.00 \\
\hline $\mathrm{Nov}_{t}$ & 5.03 & 1.70 & 2.96 & 0.00 \\
\hline$D e c_{t}$ & 37.96 & 14.60 & 2.60 & 0.01 \\
\hline $\mathrm{N}$ & 309 & Adj. $R^{2}$ & 0.52 & \\
\hline$P_{\mathrm{A}}$ & 0.09 & $P_{\mathrm{O}}$ & 0.99 & \\
\hline \multicolumn{5}{|c|}{ Panel B. Net exchanges } \\
\hline Intercept & -0.23 & 0.47 & -0.49 & 0.62 \\
\hline$\Delta a m b_{t}$ & -502.43 & 204.10 & -2.46 & 0.01 \\
\hline$\Delta c v r_{t}$ & -2.12 & 0.94 & -2.27 & 0.02 \\
\hline$a d v_{t}$ & -1.90 & 5.37 & -0.35 & 0.72 \\
\hline $\operatorname{cap}_{t}$ & 0.01 & 0.00 & 3.05 & 0.00 \\
\hline rfund $_{t-12, t-1}$ & 0.28 & 0.22 & 1.28 & 0.20 \\
\hline$r m k t_{t-3, t-1}$ & -1.02 & 0.81 & -1.25 & 0.21 \\
\hline Net exchange ${ }_{t-1}$ & 71.06 & 24.00 & 2.96 & 0.00 \\
\hline Net exchange ${ }_{t-2}$ & 10.36 & 21.80 & 0.47 & 0.64 \\
\hline Net exchange ${ }_{t-3}$ & 213.28 & 23.30 & 9.14 & 0.00 \\
\hline$I l q_{t-3, t-1}$ & -0.23 & 0.47 & 0.50 & 0.62 \\
\hline $\mathrm{N}$ & 309 & Adj. $\mathrm{R}^{2}$ & 0.04 & \\
\hline$P_{\mathrm{A}}$ & 0.17 & $P_{\mathrm{O}}$ & 0.99 & \\
\hline
\end{tabular}


Table 5: Ambiguity and Different Style Equity Funds

The table reports the estimated coefficient on the change in ambiguity for each when we estimate the models net flows (Panel A) and net exchanges models (Panel B) for the different style equity funds separately for the period March 1985 to December 2010. The variables are defined as in Table 2. $P_{\mathrm{A}}$ is the $p$-value from a Breusch-Godfrey autocorrelation test. To perform the test we first jointly estimate the models shown in equations 11 and 12 for all 5 equity categories using GMM, and then use the residuals to test whether they exhibit autocorrelation up to the sixth lag. $P_{\mathrm{O}}$ is the $p$-value from a test of over-identifying restrictions. Standard errors are adjusted for autocorrelation and heteroscedasticity using the Newey-West (1994) estimator. The classification of mutual funds is based on Kamstra et al. (2014), and is shown in Table 1. All coefficients and standard errors are multiplied by 1000 .

\begin{tabular}{|c|c|c|c|c|c|c|c|}
\hline \multicolumn{8}{|c|}{ Panel A: Net flow } \\
\hline Fund Style & Estimate & Std Err & $t$ statistic & prob $>t$ & $\mathrm{~N}$ & Adj. $R^{2}$ & $P_{\mathrm{A}}$ \\
\hline Aggressive Growth & -2939.61 & 931.40 & -3.16 & 0.00 & 309 & 0.41 & 0.75 \\
\hline Growth & -1446.01 & 482.50 & -3.00 & 0.00 & 309 & 0.36 & 0.20 \\
\hline Growth and Income & -558.95 & 198.40 & -2.82 & 0.01 & 309 & 0.66 & 0.92 \\
\hline Income Equity & -502.37 & 309.00 & -1.63 & 0.11 & 309 & 0.75 & 0.86 \\
\hline Sector & 1465.36 & 1264.40 & 1.16 & 0.25 & 309 & 0.17 & 0.31 \\
\hline \multicolumn{8}{|c|}{0.99} \\
\hline \multicolumn{8}{|c|}{ Panel B: Net exchanges } \\
\hline Aggressive Growth & -1973.21 & 689.00 & -2.86 & 0.00 & 309 & 0.16 & 0.17 \\
\hline Growth & -831.71 & 285.70 & -2.91 & 0.00 & 309 & 0.13 & 0.13 \\
\hline Growth and Income & -162.82 & 89.00 & -1.83 & 0.07 & 309 & 0.25 & 0.03 \\
\hline Income Equity & -333.22 & 141.00 & -2.36 & 0.02 & 309 & 0.50 & 0.79 \\
\hline Sector & 1143.76 & 629.90 & 1.82 & 0.07 & 309 & 0.07 & 0.00 \\
\hline$P_{\mathrm{O}}$ & 0.99 & & & & & & \\
\hline
\end{tabular}




\section{Table 6: Ambiguity and non-Equity Mutual funds}

The table reports the estimated coefficient on the change in ambiguity when we estimate the net flows (Panel A) and net exchanges models (Panel B) for the non-equity mutual funds separately for the period March 1985 to December 2010. The variables are defined as in Table 2. $P_{\mathrm{A}}$ is the $p$-value from a Breusch-Godfrey autocorrelation test. To perform the test we first jointly estimate the models shown in equations 11 and 12 for all 5 fund families using GMM, and then use the residuals to test whether they exhibit autocorrelation up to the sixth lag. $P_{\mathrm{O}}$ is the $p$-value from a test of over-identifying restrictions. Standard errors are adjusted for autocorrelation and heteroscedasticity using the Newey-West (1994) estimator. The classification of mutual funds is based on Kamstra et al. (2014), and is shown in Table 1. All coefficients and standard errors are multiplied by 1000 .

\section{Panel A: Net flow}

\begin{tabular}{cccccccc}
\hline Fund Family & Estimate & Std Err & $t$ statistic & prob $>t$ & $\mathrm{~N}$ & Adj. $^{2}$ & $P_{\mathrm{A}}$ \\
\hline $\begin{array}{c}\text { Hybrid } \\
\text { Government Fixed }\end{array}$ & -582.00 & 309.20 & -1.88 & 0.06 & 309 & 0.73 & 0.13 \\
$\begin{array}{c}\text { Income } \\
\text { Corporate Fixed } \\
\text { Income }\end{array}$ & -922.56 & 364.30 & -2.53 & 0.01 & 309 & 0.87 & 0.23 \\
Money Market & 1000.78 & 636.50 & 1.57 & 0.12 & 309 & 0.14 & 0.30 \\
\hline$P_{\mathrm{O}}$ & 0.99 & & & & & & \\
\hline $\begin{array}{c}\text { Hybrid } \\
\text { Panel B: Net exchanges }\end{array}$ & -56.63 & 41.80 & -1.35 & 0.18 & 309 & 0.61 & 0.13 \\
\hline $\begin{array}{c}\text { Income } \\
\text { Government Fixed }\end{array}$ & -358.85 & 139.30 & -2.58 & 0.01 & 309 & 0.30 & 0.03 \\
$\begin{array}{c}\text { Corporate Fixed } \\
\text { Income }\end{array}$ & -385.64 & 161.40 & -2.39 & 0.02 & 309 & 0.09 & 0.79 \\
Money Market & 223.50 & 75.70 & 2.95 & 0.00 & 309 & 0.04 & 0.00 \\
\hline$P_{\mathrm{O}}$ & 0.99 & & & & & & \\
\hline
\end{tabular}




\section{Table 7: Quarterly Regressions}

The table reports the results of estimating the net flows model (Panel A) and the net exchanges model (Panel B) for the combined equity asset class, for the period March 1985 to December 2010 using non-interpolated quarterly data. Net flows and exchanges are calculated on a quarterly basis. The changes in ambiguity and conditional variance are equal to $\Delta Q c v a r_{t}=c v a r_{t}-c v a r_{t-3}$ and $\Delta Q a m b_{t}=a m b_{t}-a m b_{t-3}$, respectively. Quarterly capital gains, savings and advertising costs are equal to the sum of the monthly values over each quarter. Lagged market return, illiquidity premium and fund return are defined as in Table 2 . In this table we include lags of one and four quarters for the dependent variable. $P_{\mathrm{A}}$ is the $p$-value from a Breusch-Godfrey autocorrelation test. To perform the test we first jointly estimate the models shown in equations 11 and 12 for all 5 fund families using GMM, and then use the residuals to test whether they exhibit autocorrelation up to the sixth lag. $P_{\mathrm{O}}$ is the $p$-value from a test of over-identifying restrictions. Standard errors are adjusted for autocorrelation and heteroscedasticity using the Newey-West (1994) estimator. The classification of mutual funds is based on Kamstra et al. (2014), and is shown in Table 1. All coefficients and standard errors are multiplied by 1000 .

\begin{tabular}{|c|c|c|c|c|}
\hline \multicolumn{5}{|c|}{ Panel A. Quarterly Net Flows } \\
\hline & Estimate & Std Err & $t$-statistic & prob $>t$ \\
\hline Intercept & -1.77 & 4.72 & -0.37 & 0.71 \\
\hline$\Delta a m b_{t}$ & -1483.41 & 355.50 & -4.17 & 0.00 \\
\hline$\Delta c v a r_{t}$ & -38.63 & 14.60 & -2.64 & 0.01 \\
\hline$a d v_{t}$ & -21.95 & 19.40 & -1.13 & 0.26 \\
\hline $\operatorname{cap}_{t}$ & -0.02 & 0.02 & -1.08 & 0.28 \\
\hline rfund $_{t-12, t-1}$ & 6.62 & 1.92 & 3.45 & 0.00 \\
\hline$r m k t_{t-3, t-1}$ & 52.60 & 5.99 & 8.78 & 0.00 \\
\hline Net flow $t-3$ & 630.61 & 29.50 & 21.38 & 0.00 \\
\hline Net flow ${ }_{t-12}$ & 109.35 & 28.20 & 3.87 & 0.00 \\
\hline$S a v_{t-3, t}$ & 42.43 & 9.05 & 4.69 & 0.00 \\
\hline$I l q_{t-3, t-1}$ & 52067.12 & 31622.60 & 1.65 & 0.10 \\
\hline Dec $_{t}$ & 9.81 & 1.36 & 7.21 & 0.00 \\
\hline $\mathrm{N}$ & 102 & Adj. $\mathrm{R}^{2}$ & 0.60 & \\
\hline$P_{\mathrm{A}}$ & 0.45 & $P_{\mathrm{O}}$ & 0.99 & \\
\hline \multicolumn{5}{|c|}{ Panel B. Quarterly Net Exchanges } \\
\hline Intercept & 0.80 & 1.52 & 0.53 & 0.60 \\
\hline$\Delta a m b_{t}$ & -684.93 & 195.70 & -3.50 & 0.00 \\
\hline$\Delta c v^{\prime} r_{t}$ & -28.95 & 4.89 & -5.93 & 0.00 \\
\hline$a d v_{t}$ & -9.65 & 5.91 & -1.63 & 0.11 \\
\hline capt $_{t}$ & 0.02 & 0.01 & 2.77 & 0.01 \\
\hline rfund $_{t-12, t-1}$ & 1.63 & 0.83 & 1.97 & 0.05 \\
\hline$r m k t_{t-3, t-1}$ & 9.26 & 2.17 & 4.27 & 0.00 \\
\hline Net exchange ${ }_{t-3}$ & 230.87 & 29.60 & 7.79 & 0.00 \\
\hline Net exchange ${ }_{t-12}$ & 49.61 & 38.80 & 1.28 & 0.20 \\
\hline$I l q_{t-3, t-1}$ & -195.61 & 15292.70 & -0.01 & 0.99 \\
\hline $\mathrm{N}$ & 102 & Adj. $\mathrm{R}^{2}$ & 0.15 & \\
\hline$P_{\mathrm{A}}$ & 0.36 & $P_{\mathrm{O}}$ & 0.99 & \\
\hline
\end{tabular}


Table 8: Additional Control Variables

The table reports the results of estimating the net flows model (Panel A) and the net exchanges model (Panel B) for the equity asset class, for the period 1986 to 2010. All the variables are defined as in Table 4. Sent is the sentiment index of Baker and Wurgler (2007) at time $t$, orthogonalized to macroeconomic variables, and Medforecast is the median SPF forecast at time $t$. The remaining variables are defined as in Table 2. $P_{\mathrm{A}}$ is the $p$-value from a Breusch-Godfrey autocorrelation test. To perform the test we first jointly estimate the models shown in equations 11 and 12 for all 5 fund families using GMM, and then use the residuals to test whether they exhibit autocorrelation up to the sixth lag. $P_{\mathrm{O}}$ is the $p$-value from a test of over-identifying restrictions. Standard errors are adjusted for autocorrelation and heteroscedasticity using the Newey-West (1994) estimator. The classification of mutual funds is based on Kamstra et al. (2014), and is shown in Table 1. All coefficients and standard errors are multiplied by 1000 .

\begin{tabular}{|c|c|c|c|c|}
\hline \multicolumn{5}{|c|}{ Panel A. Net flows } \\
\hline & Estimate & Std Err & $t$ - statistic & prob $>t$ \\
\hline Intercept & -0.30 & 1.09 & -0.27 & 0.79 \\
\hline$\Delta a m b_{t}$ & -1555.42 & 350.40 & -4.44 & 0.00 \\
\hline$\Delta c v a r_{t}$ & -4.58 & 2.14 & -2.14 & 0.03 \\
\hline$a d v_{t}$ & -2.89 & 10.20 & -0.28 & 0.78 \\
\hline $\operatorname{cap}_{t}$ & -0.43 & 0.20 & -2.09 & 0.04 \\
\hline rfund $_{t-12, t-1}$ & 1.03 & 0.55 & 1.87 & 0.06 \\
\hline$r m k t_{t-3, t-1}$ & -4.93 & 1.84 & -2.67 & 0.01 \\
\hline Net flow $t-1$ & 337.05 & 26.70 & 12.63 & 0.00 \\
\hline Net flow $t-2$ & 218.33 & 28.60 & 7.64 & 0.00 \\
\hline Net flow $t-3$ & 272.92 & 24.80 & 11.01 & 0.00 \\
\hline$s a v_{t}$ & 26.48 & 10.80 & 2.45 & 0.01 \\
\hline$I l q_{t-3, t-1}$ & 8142.06 & 18897.60 & 0.43 & 0.67 \\
\hline$J_{a n}$ & 1.50 & 0.51 & 2.96 & 0.00 \\
\hline $\mathrm{Feb}_{t}$ & -0.25 & 0.56 & -0.45 & 0.65 \\
\hline Nov $_{t}$ & 4.90 & 1.62 & 3.03 & 0.00 \\
\hline $\operatorname{Dec}_{t}$ & 35.50 & 14.30 & 2.48 & 0.01 \\
\hline Senti $_{t}$ & -0.45 & 0.28 & -1.62 & 0.11 \\
\hline Med forecast $t_{t}$ & 6.62 & 13.50 & 0.49 & 0.62 \\
\hline $\mathrm{N}$ & 309 & Adj. $R^{2}$ & 0.53 & \\
\hline$P_{\mathrm{A}}$ & 0.09 & $P_{\mathrm{O}}$ & 0.99 & \\
\hline \multicolumn{5}{|c|}{ Panel B. Net Exchanges } \\
\hline Intercept & -0.40 & 0.54 & -0.74 & 0.46 \\
\hline$\Delta a m b_{t}$ & -542.09 & 194.80 & -2.78 & 0.01 \\
\hline$\Delta c v^{\prime} r_{t}$ & -108.38 & 141.30 & -0.77 & 0.44 \\
\hline$a d v_{t}$ & -1.25 & 5.38 & -0.23 & 0.82 \\
\hline cap $_{t}$ & 0.01 & 0.00 & 3.24 & 0.00 \\
\hline rfund $_{t-12, t-1}$ & 0.32 & 0.24 & 1.35 & 0.18 \\
\hline$r m k t_{t-3, t-1}$ & -1.20 & 0.97 & -1.23 & 0.22 \\
\hline Net exchange ${ }_{t-1}$ & 75.86 & 24.40 & 3.12 & 0.00 \\
\hline Net exchange ${ }_{t-2}$ & 9.63 & 22.30 & 0.43 & 0.67 \\
\hline Net exchange ${ }_{t-3}$ & 215.72 & 25.10 & 8.61 & 0.00 \\
\hline$I l q_{t-3, t-1}$ & 3125.03 & 5476.40 & 0.57 & 0.57 \\
\hline Senti $_{t}$ & -0.12 & 0.11 & -1.08 & 0.28 \\
\hline Med forecast ${ }_{t}$ & 5.86 & 7.62 & 0.77 & 0.44 \\
\hline $\mathrm{N}$ & 309 & Adj. $\mathrm{R}^{2}$ & 0.03 & \\
\hline$P_{\mathrm{A}}$ & 0.22 & $P_{\mathrm{O}}$ & 0.99 & \\
\hline
\end{tabular}




\section{Table 9: Different Risk Measures}

The table reports the results of estimating the net flows model (Panel A) and the net exchanges model (Panel B) for the equity asset class, for the period March 1985 to December 2010. The variables are defined as in Table 2. We estimate the models using all controls as in Table 4, and only report results on the coefficients on the changes in ambiguity and the changes in risk. In each specification we use a different specification for the risk variable: $r v_{t}$ is realized volatility, is the sum of daily squared market returns using the CRSP value weighted index. $\mathrm{GARCH}_{1}$ is an in sample forecast of volatility in month $t+1$ using a simple GARCH model specification, and $\mathrm{GARCH}_{2}$ is an in sample forecast of market return volatility in month $t+1$ using the GJR GARCH model specification. The specifications of the GARCH models are taken from Glosten, Jagannathan and Runkle (1993). vix $x_{t}$ is the VXO index. For each risk measure we use the change from month $t-1$ and $t$ in our models. The fund flow regressions in Panel A where risk is measured using the GARCH models, in addition to the controls in Table 4, include a fourth lag of the dependent variable. The fund exchange regression in Panel B where risk is measured with VIX, in addition to the controls in Table 4, include a sixth lag of the dependent variable. $P_{\mathrm{A}}$ is the $p$-value from a Breusch-Godfrey autocorrelation test. To perform the test we first jointly estimate the models shown in equations 11 and 12 for all 5 fund families using GMM separately for each risk specification, and then use the residuals to test whether they exhibit autocorrelation up to the sixth lag. $P_{\mathrm{O}}$ is the $p$-value from a test of over-identifying restrictions. Standard errors are adjusted for autocorrelation and heteroscedasticity using the Newey-West (1994) estimator. The classification of mutual funds is based on Kamstra et al. (2014), and is shown in Table 1. All coefficients and standard errors are multiplied by 1000 .

\begin{tabular}{|c|c|c|c|c|c|c|c|c|}
\hline \multicolumn{9}{|c|}{ Panel A. Net flows } \\
\hline & Estimate & Std Err & $\begin{array}{c}t- \\
\text { statistic }\end{array}$ & prob $>t$ & $P_{A}$ & $\mathrm{~N}$ & $\begin{array}{l}\text { Adj. } \\
\mathrm{R}^{2}\end{array}$ & $P_{O}$ \\
\hline$\Delta a m b_{t}$ & -1500.67 & 333.6 & -4.50 & 0.00 & 0.08 & 309 & 0.53 & 0.99 \\
\hline$\Delta r v_{t}$ & -28.47 & 14.3 & -1.99 & 0.05 & & & & \\
\hline$\Delta a m b_{t}$ & -1246.75 & 281.2 & -4.43 & 0.00 & 0.09 & 309 & 0.53 & 0.99 \\
\hline$\triangle G A R C H_{1, t}$ & -276.71 & 134.5 & -2.06 & 0.04 & & & & \\
\hline$\Delta a m b_{t}$ & -1308.78 & 285.6 & -4.58 & 0.00 & 0.11 & 309 & 0.53 & 0.99 \\
\hline$\triangle G A R C H_{2, t}$ & -132.62 & 36 & -3.68 & 0.00 & & & & \\
\hline$\Delta a m b_{t}$ & -986.21 & 244.4 & -4.03 & 0.00 & 0.61 & 298 & 0.65 & 0.99 \\
\hline$\Delta v i x_{t}$ & -0.53 & 0.04 & -12.72 & 0.00 & & & & \\
\hline \multicolumn{9}{|c|}{ Panel B. Net exchanges } \\
\hline$\Delta a m b_{t}$ & -498.83 & 204.3 & -2.44 & 0.02 & 0.24 & 309 & 0.04 & 0.99 \\
\hline$\Delta r v_{t}$ & -3.1 & 7.29 & -0.43 & 0.67 & & & & \\
\hline$\Delta a m b_{t}$ & -512.01 & 207.4 & -2.47 & 0.01 & 0.12 & 309 & 0.04 & 0.99 \\
\hline$\triangle G A R C H_{1, t}$ & -209.07 & 72.7 & -2.88 & 0.00 & & & & \\
\hline$\Delta a m b_{t}$ & -502.7 & 209.1 & -2.40 & 0.02 & 0.11 & 309 & 0.04 & 0.99 \\
\hline$\Delta G A R C H_{2, t}$ & -42.91 & 15.6 & -2.75 & 0.01 & & & & \\
\hline$\Delta a m b_{t}$ & -393.28 & 128.6 & -3.06 & 0.00 & 0.07 & 298 & 0.23 & 1.00 \\
\hline$\Delta v i x_{t}$ & -0.26 & 0.03 & -9.73 & 0.00 & & & & \\
\hline
\end{tabular}




\section{Table 10: Ambiguity and the Proportion of Households that Invest in Stocks}

In this table we use data from Survey of Consumer Finances which is conducted every three years (1989 to 2010) to estimate a logistic model where the dependent variable $S M P_{i, t}$ is a binary indicator of stock market participation of household $i$. The ambiguity measure $a m b_{t-1, t-3}$ reflects the average ambiguity during the three years before year $t$ when the survey is conducted. The ambiguity measure is based on dispersion in forecasts for market returns, calculated using Equation 9. $\mathrm{vol}_{t-1, t-3}$ is the corresponding realized volatility based on the return of the CRSP value-weighted index. $A c h_{t}$ as the average Dow index price of the last year/the historical high price of Dow index until last year. The variable income $_{i, t}$ is the logged reported

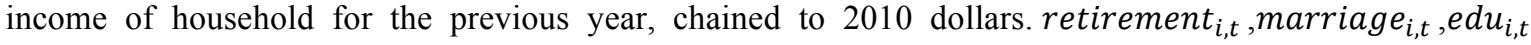
race $_{i, t}$ are dummy variables that flag whether the individual is in retirement, married, holds a college degree and white, respectively. $a g e_{i, t}$ is the reported age of respondent, and $\operatorname{riskj}_{i, t}(j=2,3,4)$ is set to 1 if the respondent has chosen answers 2, 3 or 4 when asked about her risk preferences (this question is shown in footnote 25). Standard errors are adjusted for multiple imputations.

\begin{tabular}{lccc}
\hline & Estimate & Std Err & Prob $>t$ \\
\hline amb & -255.48 & 32.14 & 0.00 \\
vol & -7.18 & 1.49 & 0.00 \\
ach & 0.78 & 0.17 & 0.00 \\
risk2 & 1.22 & 0.07 & 0.00 \\
risk3 & 1.14 & 0.04 & 0.00 \\
risk4 & 1.52 & 0.05 & 0.00 \\
edu & 0.73 & 0.03 & 0.00 \\
income & 0.62 & 0.01 & 0.00 \\
race & 0.71 & 0.04 & 0.00 \\
marriage & 0.16 & 0.04 & 0.00 \\
retirement & 0.22 & 0.06 & 0.00 \\
age & 0.03 & 0.01 & 0.00 \\
\hline $\mathrm{N}$ & 176160 & Pseudo- $\mathrm{R}^{2}$ & 0.34
\end{tabular}

